\title{
Plant Water Profiler: A Water Balance and True Cost of Water Calculator for Manufacturing Plants
}

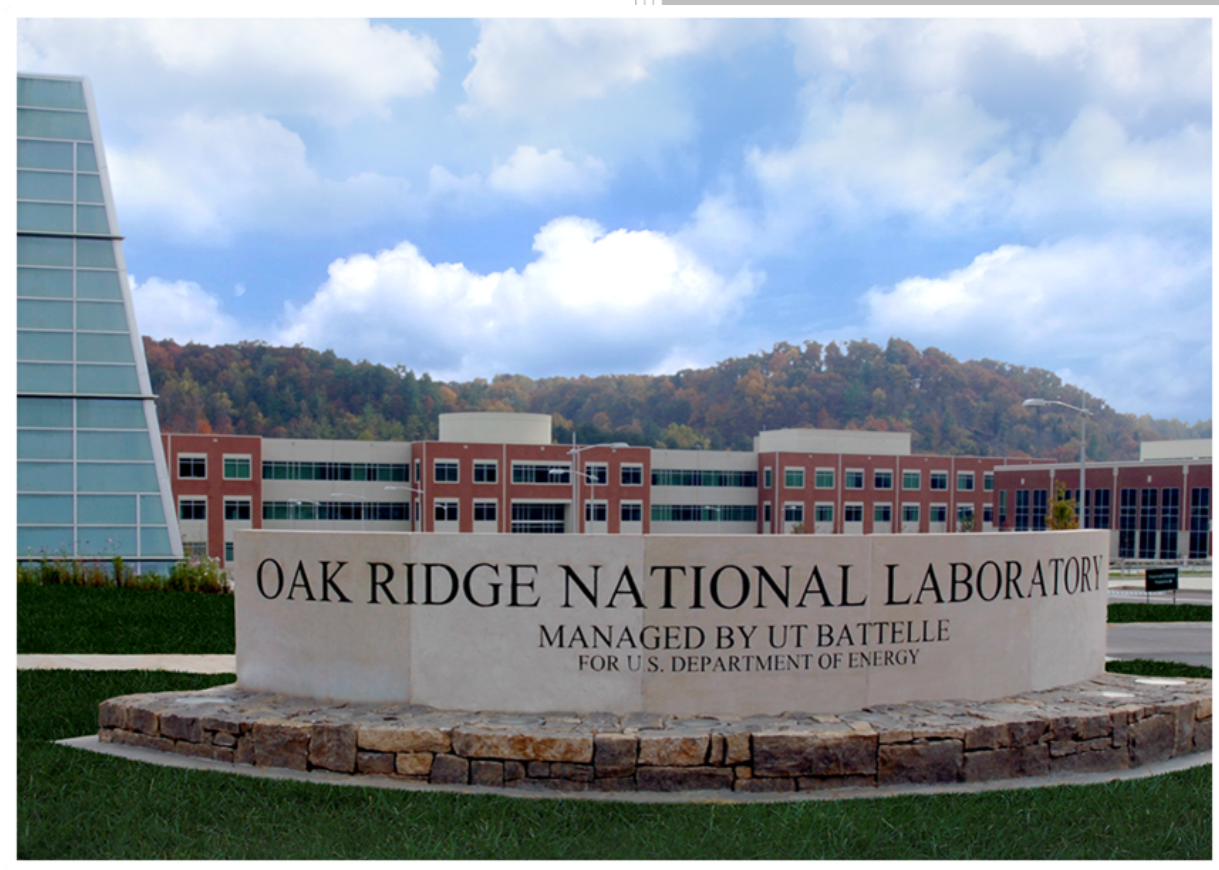

\section{Approved for public release.} Distribution is unlimited.

Mini Malhotra

Kiran Thirumaran

Susana Garcia Kristina O. Armstrong

Sachin Nimbalkar

April 2021 


\title{
DOCUMENT AVAILABILITY
}

Reports produced after January 1, 1996, are generally available free via US Department of Energy (DOE) SciTech Connect.

Website www.osti.gov

Reports produced before January 1, 1996, may be purchased by members of the public from the following source:

\author{
National Technical Information Service \\ 5285 Port Royal Road \\ Springfield, VA 22161 \\ Telephone 703-605-6000 (1-800-553-6847) \\ TDD 703-487-4639 \\ Fax 703-605-6900 \\ E-mail info@ntis.gov \\ Website http://classic.ntis.gov/
}

Reports are available to DOE employees, DOE contractors, Energy Technology Data Exchange representatives, and International Nuclear Information System representatives from the following source:

Office of Scientific and Technical Information

PO Box 62

Oak Ridge, TN 37831

Telephone 865-576-8401

Fax 865-576-5728

E-mail reports@osti.gov

Website http://www.osti.gov/contact.html

This report was prepared as an account of work sponsored by an agency of the United States Government. Neither the United States Government nor any agency thereof, nor any of their employees, makes any warranty, express or implied, or assumes any legal liability or responsibility for the accuracy, completeness, or usefulness of any information, apparatus, product, or process disclosed, or represents that its use would not infringe privately owned rights. Reference herein to any specific commercial product, process, or service by trade name, trademark, manufacturer, or otherwise, does not necessarily constitute or imply its endorsement, recommendation, or favoring by the United States Government or any agency thereof. The views and opinions of authors expressed herein do not necessarily state or reflect those of the United States Government or any agency thereof. 
Manufacturing Science Division

PLANT WATER PROFILER: A WATER BALANCE AND TRUE COST OF WATER CALCULATOR FOR MANUFACTURING PLANTS

\author{
Mini Malhotra \\ Kiran Thirumaran \\ Susana Garcia \\ Kristina O. Armstrong \\ Sachin Nimbalkar
}

Date Published: April 2021

\author{
Prepared by \\ OAK RIDGE NATIONAL LABORATORY \\ Oak Ridge, TN 37831-6283 \\ managed by \\ UT-BATTELLE, LLC \\ for the \\ US DEPARTMENT OF ENERGY \\ under contract DE-AC05-00OR22725
}





\section{CONTENTS}

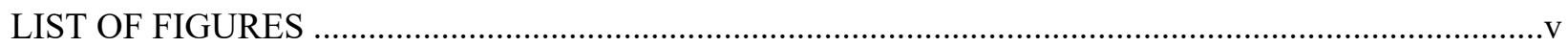

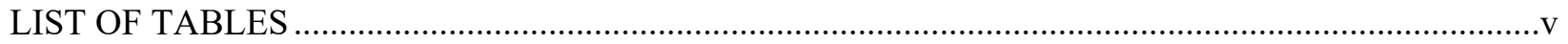

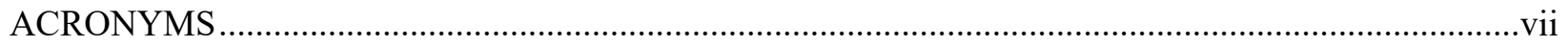

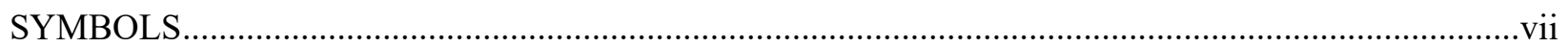

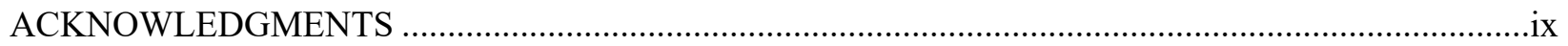

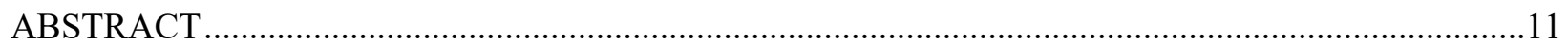

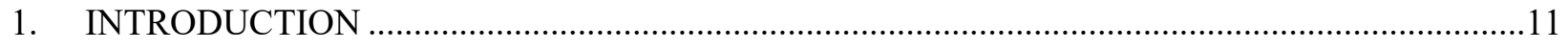

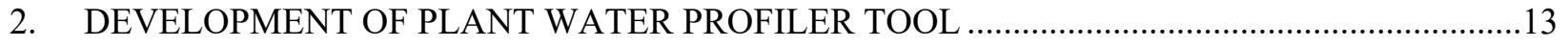

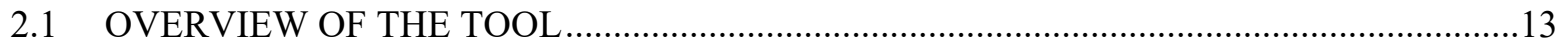

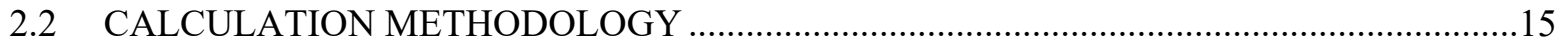

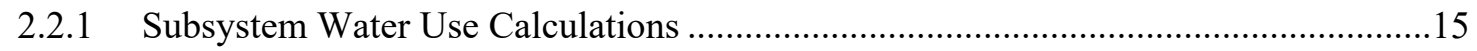

2.2.2 Water Flow Model, Water Balance Calculations, and Calibration...............................17

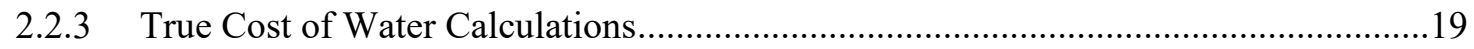

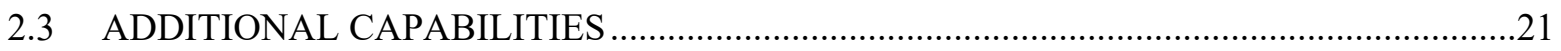

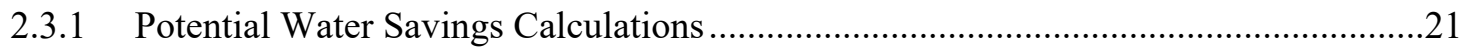

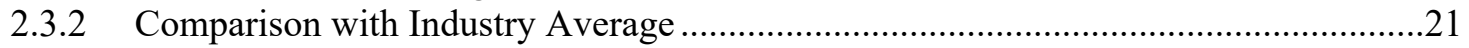

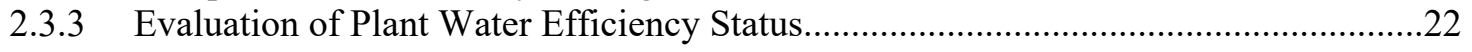

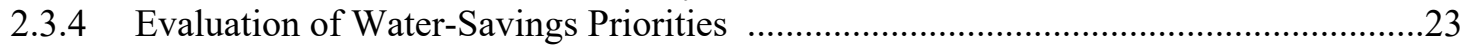

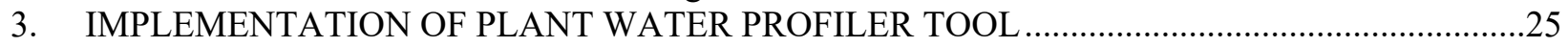

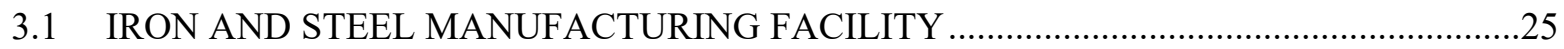

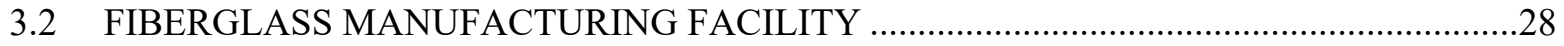

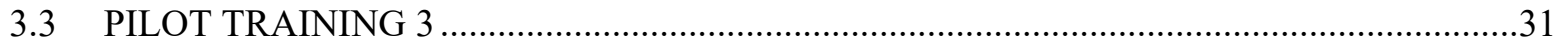

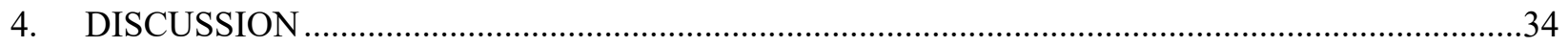

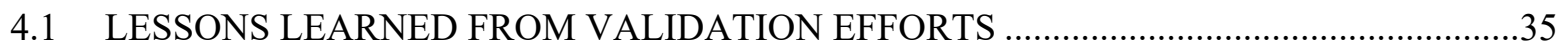

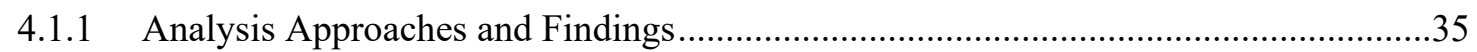

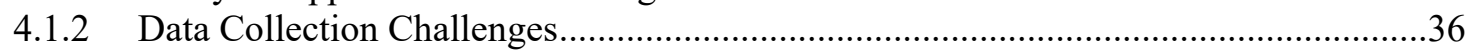

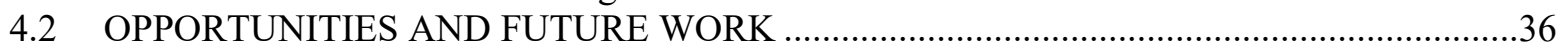

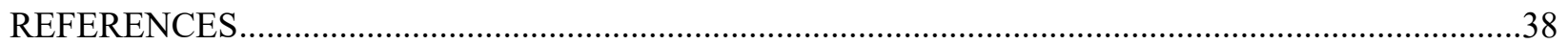





\section{LIST OF FIGURES}

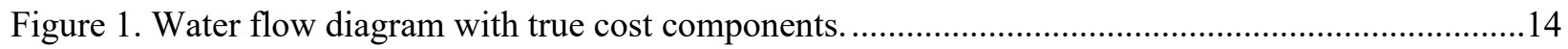

Figure 2. Water flow model with respect to a generic subsystem " $x$ " .............................................18

Figure 3. Panel a): Water balance for a subsystem. Panel b): water balance for the whole facility............19

Figure 4. Example of breakdown and comparison of source water intake and true cost...........................23

Figure 5. Water flow diagram for the cold mill of an iron and steel manufacturing plant.........................26

Figure 6 . Water use and true cost by subsystem and cost component for the iron and steel

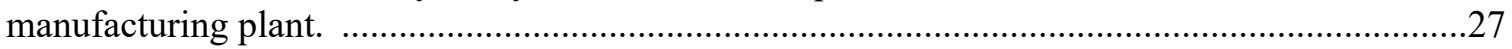

Figure 7. True cost of water by subsystem (rows) and by cost components (columns) for the cold

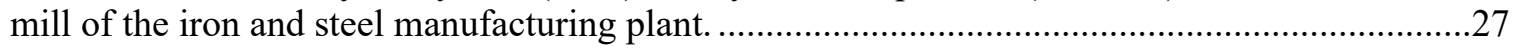

Figure 8. Water flow diagram for a fiberglass manufacturing plant (Pilot Training 2)............................29

Figure 9. Water use and true cost by subsystem and cost component for the fiberglass

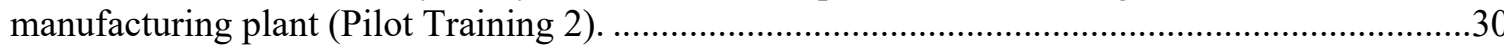

Figure 10. True cost of water by subsystem (rows) and by cost components (columns) for the

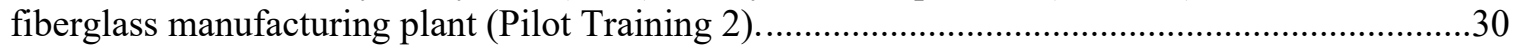

Figure 11. Water flow diagram for a vinyl siding manufacturing plant (Pilot Training 3).....................32

Figure 12. Water use and true cost by subsystem and cost component for the vinyl siding

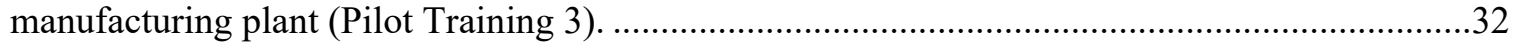

Figure 13. True cost of water by subsystem (rows) and by cost components (columns) for the

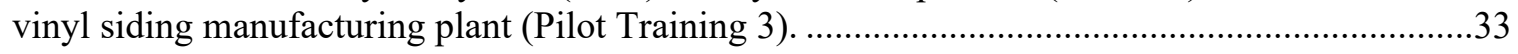

\section{LIST OF TABLES}

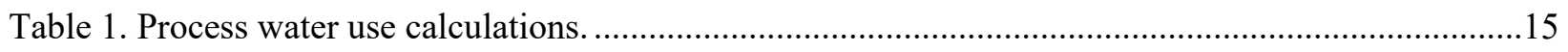

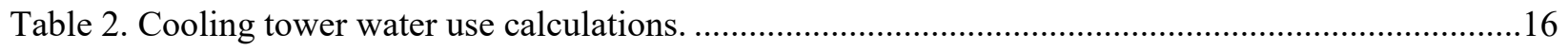

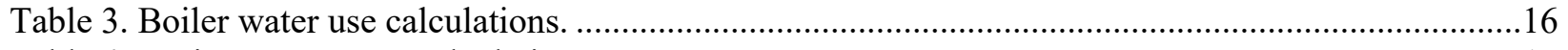

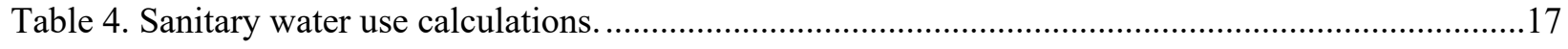

Table 5. Landscaping and irrigation water use calculations. ................................................................17

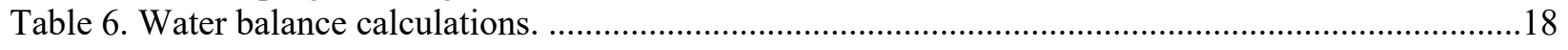

Table 7. The five-step methodology to estimate the true cost of water.................................................20

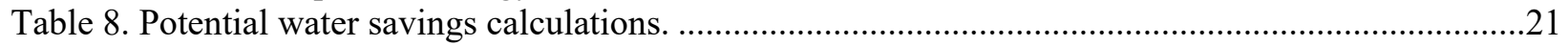

Table 9. Example plant and subsystem water efficiency status evaluation questionnaire........................22

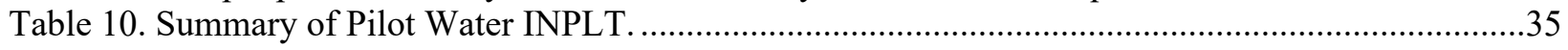





\section{ACRONYMS}

EIO-LCA Economic Input-Output Life Cycle Assessment

INPLT in-plant training

NAICS North American Industry Classification System

PWP Plant Water Profiler Tool

STATCAN Statistics Canada

\section{SYMBOLS}

$\mathrm{X}$

$\mathrm{S}$

$\mathrm{p}$

o

$\mathrm{t}$

t'

d

$\mathrm{I}_{\mathrm{X}, \mathrm{S}}$

$\mathrm{R}_{\mathrm{X}}$

$\mathrm{R}_{\text {in, } \mathrm{X}^{\prime}}$

$\mathrm{R}_{\text {out, } \mathrm{X}^{\prime}}$

$P_{\mathrm{X}}$

$\mathrm{E}_{\mathrm{X}}$

$W_{\mathrm{X}, \mathrm{O}}$

$\mathrm{L}_{\mathrm{X}}$

$\mathrm{T}_{\mathrm{X}, \mathrm{t}}$

$\mathrm{T}_{\mathrm{x}, \mathrm{t}}^{\prime}$

Elec $_{\mathrm{x}}$

Fuel $_{x}$

$\$_{\mathrm{S}}$

$\$_{0}$

$\dot{\$}_{\mathrm{t}}$

$\$_{\text {elec }}$

$\$_{\text {fuel }}$

MGPY water using subsystem $\mathrm{x} ; \mathrm{x}=1$ to $\mathrm{X}$

water intake source $s ; s=1$ to $S$

product $\mathrm{p} ; \mathrm{p}=1$ to $\mathrm{P}$

wastewater discharge outlet $\mathrm{o} ; \mathrm{o}=1$ to $\mathrm{O}$

water treatment process $t, t=1$ to $T$

wastewater treatment process $t^{\prime}, t^{\prime}=1$ to $T^{\prime}$

depth of irrigated water

water intake by system $\mathrm{x}$ from source $\mathrm{s}$

water recirculated within system $\mathrm{x}$

water incoming from other subsystems to subsystem $\mathrm{x}$

water outgoing to other subsystems from subsystem $\mathrm{x}$

water used in products by subsystem $\mathrm{x}$

evaporation or irrigation loss associated with subsystem $\mathrm{x}$

wastewater discharge from subsystem $\mathrm{x}$ to outlet $\mathrm{o}$

unknown loss associated with subsystem $\mathrm{x}$

water treated by process $t$

wastewater treated by process $t^{\prime}$

electricity consumption by subsystem $\mathrm{x}$

heating fuel consumption by subsystem $\mathrm{x}$

unit cost of water intake from source $s$

unit cost of wastewater discharge to outlet o

unit cost of water or wastewater treatment $t$

unit cost of electricity

unit cost of heating fuel

million gallon per year 



\section{ACKNOWLEDGMENTS}

The authors gratefully acknowledge the support and guidance of Andre de Fontaine and Sandy Glatt of US Department of Energy and Joseph Cresko of the US Department of Energy's Advanced

Manufacturing Office. The authors also thank Sujit Das, Daryl Cox, and Wei Guo of Oak Ridge National Laboratory for their support during the development of the Plant Water Profiler tool; Prakash Rao of Lawrence Berkeley National Laboratory; Alberta Carpenter and James McCall of the National Renewable Energy Laboratory; and Sarang Supekar of Argonne National Laboratory, who reviewed a draft of this report and provided valuable comments. The authors also greatly appreciate the support and participation of their industry partners. 



\begin{abstract}
As the uncertainty of a sustained water supply, regulatory constraints, competition among end users, and public scrutiny increases, a growing number of manufacturing sectors are adapting to current and emerging water-related risks by optimizing productivity and reducing waste. As a step toward increasing water use efficiency and making informed business decisions, corporations must make an effort to understand and track their water demands, losses, and costs associated with each subsystem within their facilities.

Manufacturers are often unaware of the "true cost of water" (i.e., the total costs associated with procurement, treatment, and consumption of water, and wastewater disposal), which reduces the visibility of the actual impact of water-saving measures. To help manufacturers account for water procurement and use in manufacturing operations, quantify the true cost of water, and identify potential areas for water and associated energy cost savings, an open access tool-Plant Water Profiler (PWP)—was developed. The tool is based on water mass balance analysis and has been adopted as the core analysis tool for plant water use assessments, Water In-Plant Training (Water INPLT), as part of the US Department of Energy's Better Plants program. During three pilot INPLTs conducted in 2019 at three manufacturing facilities, the PWP tool allowed users to understand water flows within the facilities and provided additional capabilities to analyze their water use. This paper describes the methodology behind the PWP tool and its implementation through pilot Water INPLT trainings delivered in three manufacturing facilities in the United States. The three case studies demonstrate opportunities to improve water efficiency and reduce associated costs and the challenges encountered in three different manufacturing sectors.
\end{abstract}

\title{
1. INTRODUCTION
}

As the uncertainty of sustained water supply (Borgomeo, Hall, \& Guillod, 2018; Orr, Cartwright, \& Tickner, 2009), regulatory constraints (Gouws, Majozi, Foo, Chen, \& Lee, 2010), competition among end users (UN, 2007), and public scrutiny increases (Morrison, 2009), a growing number of manufacturing sectors are adapting to current and emerging water-related risks by optimizing productivity and reducing waste. As a step toward greater water use efficiency, corporations must understand and track the water demands of each of the main water-using components in their facilities (Larson, 2012). Besides the benefits to the surrounding environment, improvements in water efficiency can be coupled with energyefficient practices and a reduction of costs (EPA, 2011). The true cost of water in a facility goes beyond the price paid for water acquisition and must be quantified in the context of a water-energy nexus (e.g., cost of energy for water extraction and pumping) and account for changes in water quality (e.g., cost of treatment and disposal). To support the manufacturing sector in identifying opportunities for water use efficiency and assessing the true cost of water, Oak Ridge National Laboratory (ORNL) developed a Plant Water Profiler (PWP) tool. This report describes the development and capabilities of the tool as well as summarizes the results from three pilot water assessments performed by ORNL using the PWP tool.

The PWP tool is an open-access tool designed to help facilities understand their water balance, cost, and opportunities for water saving. Unlike commonly used tools, PWP is applicable to any manufacturing sector, allows the assessment of water balance, estimates the true cost of water, and provides results at a subsystem level. Several tools have been developed in the past to manage water use [e.g., spreadsheets, audits, and scorecards (AWWA, 2006; EDF-GEMI, 2014; FEMP, 2016)] and assess facility water balance [e.g., GEMI's Collecting the Drops (GEMI, 2002), Blue Plan-It (Carollo, 2016)] and the true cost of water (BIER, 2018; Colgate-Palmolive, 2015; Veolia, 2013). Moreover, large water-intensive companies have also developed their own systems as part of their environmental stewardship programs [e.g., PepsiCo Resource Conservation (ReCon) (PepsiCo, 2017), Nestle Environmental Management System (NEMS) (Nestlé, 2013)]. The PWP tool encompasses the capabilities of true cost calculators, the simplicity of water balancing tables for data input, and the flexibility to estimate water use for subsystems 
in the absence of comprehensive submetering. The tool has been implemented by ORNL in partnership with three manufacturing facilities through the US Department of Energy's (DOE's) Better Buildings, Better Plants program (U.S. Department of Energy, 2014, 2016). The water assessment was accompanied by an In-Plant Training (INPLT) at such facilities and identification of water-saving opportunities through a treasure hunt inspection modality. The subsequent analysis encompassed a water balance calculation, determination of the true cost of water, and identification of opportunities for improvement. Section 2 of this report summarizes the calculation methodology and tool capabilities.

While the manufacturing sector is responsible for a relatively small portion of national water use, water conservation potential can vary greatly among technologies, industries, and regions, presenting a unique challenge for stakeholders (Gleick, 2003). In 2015, the manufacturing sector accounted for about $6 \%$ of total US water use (Rao, Sholes, Morrow, \& Cresko, 2017), including 5\% as self-supplied withdrawal from surface-water and groundwater sources (Dieter et al., 2018) and 1\% through public water supplies (Becker, 2015; Solley, Pierce, \& Perlman, 1998). ${ }^{1}$ Although national-level manufacturing water use data are scarce, past national surveys (Becker, 2015; Kenny et al., 2009), homologous surveys for other nations (Renzetti, 1993), and corporate sustainability reporting (CDP, 2018) have shown that there is heterogeneity in water use volumes, water sources, quality requirements, reuse and recirculation, and disposal practices across industries technologies and regions. Some of the sectors found to be the largest water users are pulp and paper, primary metals, chemicals, petroleum and coal, and food, accounting for more than $90 \%$ of manufacturing water intake (Rao et al., 2017; Peter Rogers, 1993). Within manufacturing facilities, water demand also varies among processes, equipment, and subsystems, which are generally divided into three macro-purposes: process water, water for cooling, and water for heating (Ellis, Dillich, \& Margolis, 2001). The major uses of water in the studied facilities were found to be for processes and cooling, accounting for, at least, $98 \%$ of freshwater intake. Over time, plants have transitioned from inefficient practices such as "once-through" cooling systems to more efficient "closed-loop" cooling (Dorjets, 2014), which recirculates water within cooling towers. Although it is more prevalent in waterintense sectors (Peter Rogers, Llamas, \& Martinez-Cortina, 2006), the implementation and optimization of water recirculation can significantly reduce a facility's dependence on freshwater. For instance, a fiberglass manufacturing facility freshwater intake was found to be less than $4 \%$ of its gross use of water (i.e., intake water and recirculation; see Section 3.2), reflecting the importance of water recirculation.

Section 3 summarizes the findings, challenges, and opportunities observed during the implementation of the PWP tool for the three facilities studied in three different manufacturing sectors (steel, fiberglass, and construction materials), highlighting the possibility of using the tool despite the inherent differences in their operations. Some of the major challenges during the implementation of the tool were the lack of submetering and tracking of water uses at the subsystem level and the lack of metering of self-supplied water (i.e., surface water or groundwater not supplied or billed by municipal utility services). Without adequate submetering, the tool requires the estimation of water use based on equipment-specific operation parameters (e.g., cooling tower load, cooling tower makeup water conductivity, boiler horsepower) and may not reflect water flows accurately. The water mass balance of the facilities was assessed at the subsystem and facility level by comparing metered, estimated, and billed water flows when available; imbalances reflected water losses, unaccounted flows, or inaccurate estimations. Subsequent to the assessment of the water mass balance, the tool was used to estimate the true cost of water by accounting for all the direct costs associated with the procurement, use, disposal, and treatment of water. The true cost quantification reflected that facilities could be spending up to three times their billed cost of water.

\footnotetext{
${ }^{1}$ Public-supply deliveries to commercial, industrial, and thermoelectric-power users have not been reported by USGS since 1995. According to Dieter et al. (2018), self-supplied industrial water withdrawal was 5\% of total US water use in 2015 . As reported in Becker (2015), about 82\% of industrial water was self-supplied (Solley et al., 1998), the last year this estimate was made. Assuming this same proportion, total manufacturing water intake in 2015 was approximately $0.05 / 0.82=6.1 \%$.
} 


\section{DEVELOPMENT OF PLANT WATER PROFILER TOOL}

Several tools have been developed in the past to help facilities estimate their true cost of water. Some of the widely known tools are designed for a specific manufacturing sector (e.g., BIER, 2018), are proprietary tools for specific corporations (e.g., PepsiCo, (2017), or are not accessible free of charge (e.g., Veolia, (2013). While the range of complexity in the tools varies from spreadsheet-based tools to webbased platforms, the first step in determining the true cost of water is accurate water accounting. A number of studies use the water mass balance framework for water accounting, monitoring, and optimal operation in a variety of contexts [e.g., in industrial parks (Pham et al., 2016); urban environments (Kenway, Gregory, \& McMahon, 2011)]. Kurle, Herrmann, \& Thiede (2017) presented a structured approach to identify and visualize water-related hot spots in manufacturing sites, supported by generic modeling tools available to facilities. Sachidananda and Rahimifard (2012) presented a transparent methodology for minimizing water use within manufacturing processes and a decision support tool for testing scenarios. The PWP tool uses a water mass balance framework to account for flows within a facility, allowing for different sources of water, treatment, recirculation, and disposal. The tool is presented as an excel spreadsheet that is accessible to facilities, with a transparent methodology that aids manufacturing sites identifying unaccounted flows and hidden costs, at the subsystem or equipment aggregation desired by the facility.

A subsequent step in the water profiling is establishing the energy-water connection by accounting for energy use associated with water uses. Many studies performing water use modeling have also expanded to analyze the water-energy interdependence. Mousavi, Kara, \& Kornfeld (2015) introduced a simulationbased approach based on a water footprint methodology to model energy and water flows in manufacturing systems. Thiede, Schonemann, Kurle, \& Herrmann (2016) modeled the interdependence of water and energy flows among facilities' processes, machines, products, and resources in a dynamic way that other methodologies such as material flow analysis cannot incorporate. The PWP tool acknowledges the energy-water interdependence by accounting for energy used for water pumping and the fuel associated with unrecovered heat in wastewater.

Finally, the true cost of water is estimated using information from the water balance model, the energywater connections, and additional direct operational costs. The essential cost components of the true cost of water include the costs of water procurement, treatment, processing, and its use in water-using subsystems and processes in the facility over a specific period (Henderson, Somers, \& Stuchtey, 2013; Rao, McKane, \& Fontaine, 2015). Walsh, Bruton, \& O'Sullivan (2017) have used the term "true value" to account for the financial value-added costs involving labor, materials, energy, and equipment required for operations such as purification, chemical treatment, and disposal, as well as all installation and operation costs. Veolia's True Cost of Water tool (Veolia, 2013) accounts for direct costs (for procurement, operation, and investments in water infrastructure)and indirect costs (administrative, legal, and corporate social responsibility costs, and costs related to risks such as operational, financial and regulatory, and reputational risks). The PWP tool adopts the terminology of Rogers, de Silva, \& Bhatia (2002) in which the price of water refers to the tariffs paid to municipalities for water acquisition and the cost is accounted for through the direct operational costs associated with water procurement, treatment, and disposal. Indirect administrative costs, legal costs, and capital expenditures are not currently accounted for.

\subsection{OVERVIEW OF THE TOOL}

PWP starts by defining the boundary of the analysis as a system with its corresponding subsystems in which water is used. The analyzed system can be an entire facility or a group of processes, while the subsystems can be a specific process (e.g., assembly, casting, coating), equipment (boiler, chiller, cooling tower), operation (heating, cooling, pumping, power generation), ancillary service (e.g., landscaping, 
kitchen, toilets), or a combination of them (e.g., cooling for processes, cooling for power generation, boiler for power generation). When information of inflows, outflows, and recirculation for each subsystem is provided or estimated, the PWP tool can assist in identifying unaccounted flows and losses and compare water use across subsystems.

The tool also allows the user to assign a cost associated with water uses. The cost can be explicitly associated with water procurement, treatment, and disposal or hidden in the connections between energy and water such as electricity used for water transport and fuel use associated with unrecovered heat energy in wastewater that leaves the plant boundary.

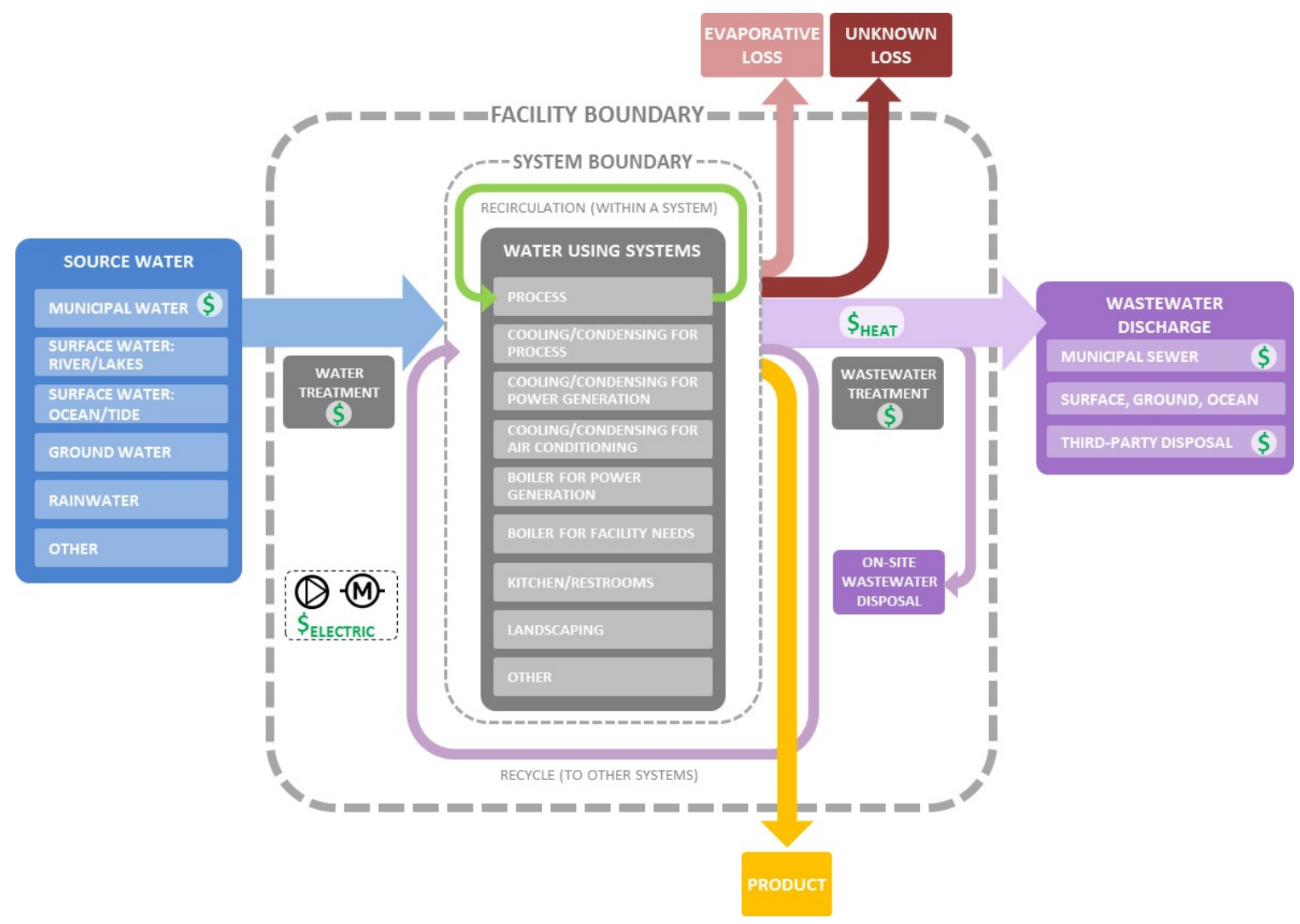

Figure 1. Water flow diagram with true cost components.

Figure 1 shows the definition of boundary around the analyzed system (plant) and its water-using subsystems. The illustration shows the possible water flows that are used to compute the water mass balance. Inflows from different sources are shown in blue, wastewater generated is shown in purple, water incorporated in products is shown in yellow, water recirculation is shown in green, and water losses are shown in red. The dollar sign symbolizes the costs that are used to compute the true cost of water.

The PWP tool, by analyzing water flows at the subsystem scale, allows facilities to identify, compare, and rank subsystems by their share of intake water use. Additionally, by coupling water volumes to water costs, the tool contrasts the volume of water to the cost for each subsystem. Through this step, the tool identifies instances such as subsystems that require small volumes of high-cost water and vice versa.

Further, PWP assesses the water efficiency status of a plant and its individual subsystems by providing a tailored list of water-efficiency measures and opportunities specific to the plant. Thus, PWP is a first step 
that industrial manufacturing plants can take to identify opportunities for minimizing water use and reducing cost.

\subsection{CALCULATION METHODOLOGY}

PWP uses a systematic water mass-balance framework to characterize inflows, outflows, and recirculation for each of its subsystems and identifies unaccounted flows by assessing the closure of the water massbalance. While the tool is capable of using high granularity data, submetering of water flow is usually rare in industrial settings because of (1) high upfront installation cost and high, recurring maintenance expenses, (2) monthly service charges for specialized assistance with meter reading and allocation, (3) regulatory issues involving permits, inspections, and fees for submetering equipment (City of Richmond; City of San Diego, 2020), and (4) liability concerns related to system malfunction and leaks (Fehl, 2017). Therefore, the user inputs for unmetered subsystem-level water flow can be unreliable. PWP guides the estimation of water flows in different subsystems via a bottom-up approach that uses equipment-specific operation parameters (Section 2.2.1).

The aggregation of all subsystem estimates provides estimated facility-level water flows. The model calibration portion takes a top-down approach that uses plant-level utility bills or metered data for water intake and effluent and compares it with the aggregation of subsystem estimated volumes. Disparities between both approaches (top-down and bottom-up) at the facility level or a failure to match inflows and outflows at the subsystem level indicate the presence of unaccounted for flows that must be investigated and manually corrected within the tool.

The inputs and calculations programmed in PWP are outlined in the following sections.

\subsubsection{Subsystem Water Use Calculations}

Once all the water-using subsystems have been defined by the user, specific parameters of processes and equipment can be specified. The parameters are used to calculate specific water intake, recirculation, gross water use, consumptive water use, and effluent. Tables 1-5 show the parameters that users can specify for processes, cooling towers, boilers, and ancillary services such as sanitary use and landscaping, respectively. The left-side column in each table shows the inputs required by the user, and the right-side column shows the calculations performed by the tool.

For processes (Table 1), parameters include estimates of the number of production units, process water use, water incorporated in products per production unit, and recirculation ratios to calculate the volumes of total water use, consumptive water use, and recirculated water.

Table 1. Process water use calculations.

User Inputs Calculations

For subsystem $\mathbf{x}=$ Process:

N: Number of Units Processed per Year (units)

g: Water Use (gal per production unit)

r: Fraction Recycled or Reused

p: Water Consumed in Product (gal per production unit)
Gross Water Use, $G_{x}=N * g / 10^{6}$ (MGPY)

Recirculated Water, $R_{x}=G_{x} * r$ (MGPY)

Makeup Water, $M_{x}=G_{x}-R_{x}$ (MGPY)

Water Consumed in Products, $P_{x}=N * p / 10^{6}$ (MGPY) 
For cooling towers (Table 2), annual hours of operation, tonnage, load fraction, evaporation rate, temperature drop across cooling tower, makeup water, and blowdown conductivity measurements are used to calculate makeup water (water intake), gross water use and recirculated water, evaporation loss (consumptive use), and blowdown (effluent). The estimation of the gross water use follows the rule-ofthumb of 3 gallons per minute per ton of cooling (i.e., tonnage * load fraction) (Boyd, 2011). The water loss due to drift is ignored. Evaporation rate is entered as a percentage of gross water use per $10^{\circ} \mathrm{F}$ temperature drop, which is typically $0.85 \%$, with a typical range of $1.0-1.2 \%$ for dry climate to $0.65 \%$ for moist climate (CheCalc, 2017). For once-through cooling systems, water intake and discharge are calculated from the water flow rate (in gallons per minute) and hours of operation.

Table 2. Cooling tower water use calculations.

User Inputs Calculations

For subsystem $x=$ Cooling Tower:

H: Hours of Operation per Year (hours)

CT: Chiller or Cooling Tower Tonnage

L: Load as a Fraction of Tonnage

e: Evaporation Rate per $10^{\circ} \mathrm{F}$ Temp. Drop (\%) Makeup Water, $M_{x}=E_{x} /(1-1 / C)(\mathrm{MGPY})$

$\Delta \mathrm{T}$ : Temp. Drop Across Cooling Tower $\left({ }^{\circ} \mathrm{F}\right) \quad$ Blowdown, $B_{x}=M_{x}-E_{x}$ (MGPY)

Mc: Makeup Water Conductivity (selected unitRecirculated Water, $R_{x}=G_{x}-M_{x}$ (MGPY)

Bc: Blowdown Conductivity (selected unit)

For subsystem $x=$ Once-through Cooling:

H: Hours of Operation per Year (hours)

F: Water Flowrate (gal per minute)
Evaporation Loss, $E_{x}=G_{x} *(e / 100) * \Delta T / 10(\mathrm{MGPY})$

Cycles of Concentration, $C=B c / M c$
Water Intake $=$ Gross Water Use $=$ Discharge Water $=F * H * 60 / 10^{6}(\mathrm{MGP}$

For boilers (Table 3), annual hours of operation, boiler capacity, load fraction, steam generation rate, and makeup water, feedwater and blowdown conductivity measurements to calculate makeup water (water intake), feedwater (gross water use), steam losses (water consumption), condensate return (recirculated water), and blowdown (wastewater discharge) (Boyd, 2011). Losses in deaerator are ignored.

Table 3. Boiler water use calculations.

\begin{tabular}{ll}
\hline User Inputs & Calculations
\end{tabular}

For subsystem $\mathbf{x}=$ Boiler:

H: Hours of Operation per Year (hours)

BHP: Boiler Horsepower

L:Load as a Fraction of Boiler Horsepower

e: Steam Generation Rate $(\mathrm{lb} / \mathrm{h})$ per BHP

Fc: Feedwater Conductivity (selected unit)

Mc: Makeup Water Conductivity (selected unit)

Bc: Blowdown Conductivity (selected unit)
Cycles of Concentration, $C=B c / F C$

Gross Water Use, $G_{x}=[e /(1-1 / C)] * B H P * L * 0.002 * H$ * 60/106 (MGPY)

Makeup Water, $M_{x}=\left(F_{c} / M_{c}\right) * G_{x}(\mathrm{MGPY})$

Blowdown, $B_{x}=(1 / C) * G_{x}(\mathrm{MGPY})$

Evaporation Loss, $E_{x}=M_{x}-B_{x}$ (MGPY)

Recirculated Water, $R_{x}=G_{x}-M_{x}$ (MGPY) 
For kitchens and restrooms (Table 4), the number of employees, work hours, and estimates of water use per employee are used to calculate the total water use. The user may estimate water use per employee based on a typical range of 10 gallons per shift when only toilets are used to 35 gallon per shift where there are toilets, showers, and full kitchen services (e.g., food preparation and dishwashing) (EPA, 2011).

Table 4. Sanitary water use calculations.

\begin{tabular}{ll}
\hline User Inputs & Calculations \\
\hline For subsystem $\mathbf{x}=$ Kitchen and Restrooms: & \\
N: Number of Employees (employees) & Gross Water Use, $G_{x}=N_{x} * D_{x} * g / 10^{6}(\mathrm{MGPY})$ \\
D: Work Days per Year (days) & \\
g: Water Use per Employee (gal per day) &
\end{tabular}

For landscaping and irrigation (Table 5), the area of land irrigated and inch of irrigated water per unit area of land are used to calculate irrigation water consumption.

Table 5. Landscaping and irrigation water use calculations.

\begin{tabular}{ll}
\hline User Inputs & Calculations \\
\hline For subsystem $\mathbf{x}=$ Landscaping and Irrigation: & \\
A:Square Feet of Land Irrigated (sq. ft) & Gross Water Use, $G_{x}=0.623 * d * A * D / 10^{6}(\mathrm{MGPY})$ \\
d: depth of of Irrigated Water per Year (in.) & Irrigation Water Consumption, $E_{x}=G_{x}(\mathrm{MGPY})$
\end{tabular}

Subsystem water use calculations are optional but recommended, especially for unmetered subsystems. The accuracy of these estimates depends on the quality of the user-provided information. These estimates are used only to inform the subsystem gross water use and water outflow breakdown to generate the water flow model.

\subsubsection{Water Flow Model, Water Balance Calculations, and Calibration}

To develop the water flow model in a plant, the breakdown of subsystems' gross water use and water outflows is required as user input. Because water use is rarely metered at the subsystem level, the calculated subsystem water use (as outlined in Section 2.2.1) provides a starting point for facilities to characterize their flows.

Figure 2 shows the water flow model with respect to a generic subsystem " $x$ " (solid arrows). The subsystem $x$ has its corresponding source water inflow $I_{x}$ from source $I_{s}$, wastewater discharge $W_{x}$ at wastewater discharge outlet $W_{o}$, evaporative loss $E_{x}$, unknown losses $L_{x}$, recirculated water $R_{x}$, and water incorporated in products $P_{x}$ leaving the system boundary. Dotted arrows are flows associated with the remainder of subsystems in the facility. The blue arrows indicate source water intake, and green arrows indicate recirculation within the subsystem or shared with other subsystems within the facility. Purple and red arrows indicate water that leaves the facility as wastewater or losses, incorporated in products, respectively. Table 6 shows the user inputs and the calculations performed by the tool to determine the flows associated with a generic subsystem $x$ within a facility. 


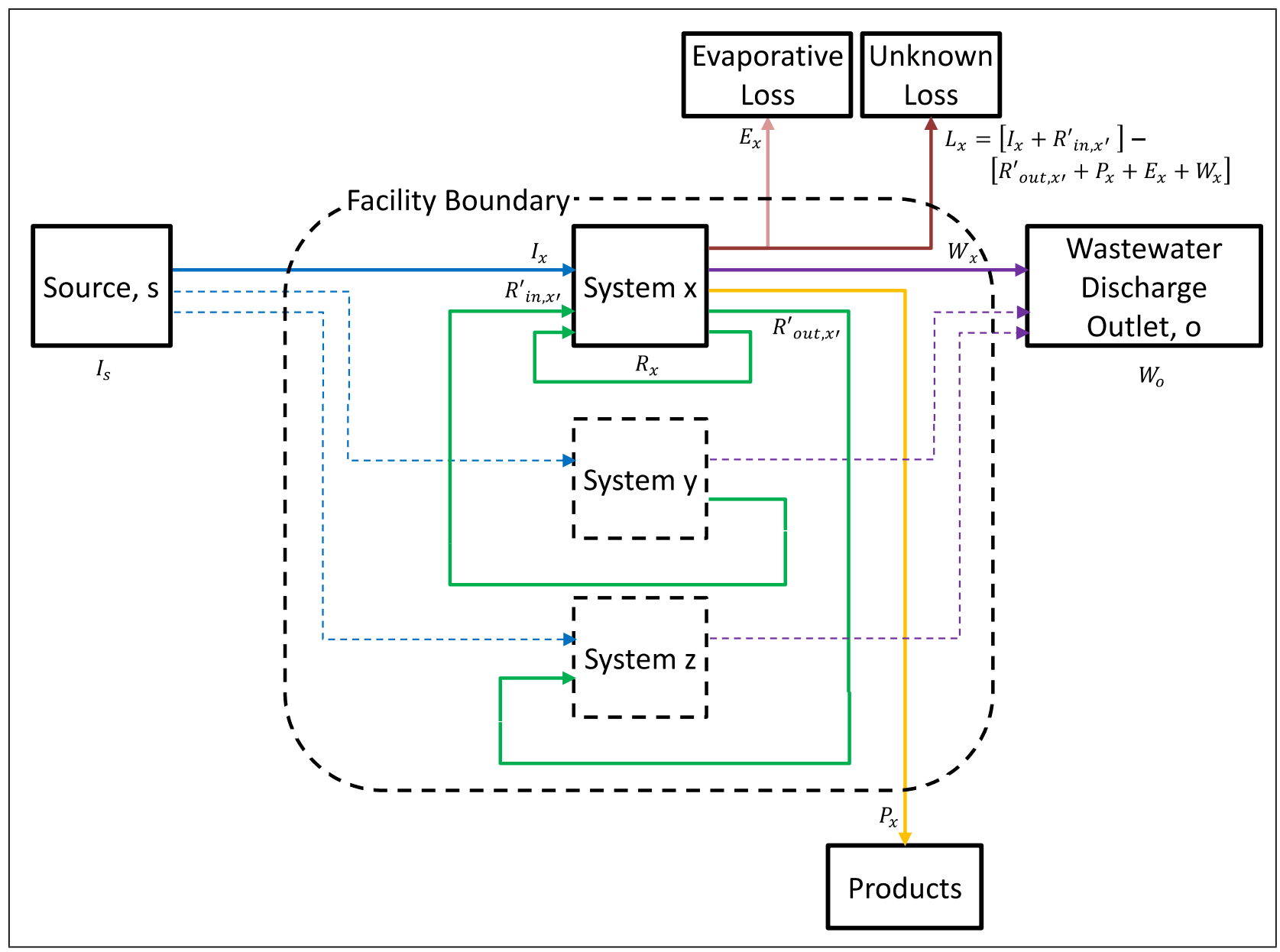

Figure 2. Water flow model with respect to a generic subsystem " $x$ ".

Table 6. Water balance calculations.

User Inputs

Plant Water Intake and Wastewater Discharge

$\mathrm{I}_{\mathrm{S}}$ :Plant Water Intake by Source (MGPY)

$\mathrm{W}_{\mathrm{o}}$ :Plant Wastewater Discharge by Outlet (MGPY)

Subsystem Gross Water Use

$\mathrm{I}_{\mathrm{X}}$ : Source Water Use (MGPY)

$\mathrm{R}_{\mathrm{in, \textrm {x } ^ { \prime }}}$ : Water from Other Subsystems (MGPY)

$\mathrm{R}_{\mathrm{x}}$ : Recirculated Water (MGPY)

\section{Subsystem Water Outflow}

$\mathrm{W}_{\mathrm{x}}$ : Wastewater Discharge (MGPY)

$\mathrm{R}_{\text {out }, \mathrm{X}^{\prime}}$ : Water to Other Subsystems (MGPY)

$\mathrm{E}_{\mathrm{X}}$ : Consumptive Loss (MGPY)

$\mathrm{P}_{\mathrm{X}}$ : Water Incorporated in Product (MGPY)

\section{Calculations}

Water Flow Model Calibration:

$\sum_{x} I_{x}=\mathrm{I}_{\mathrm{s}}$

$\sum_{x} W_{x}=W_{o}$

Unknown water loss in subsystem $\mathrm{x}$,

$\mathrm{L}_{\mathrm{x}}=\left[I_{x}+R_{\text {in, } x^{\prime}}^{\prime}\right]-\left[{R^{\prime}}_{\text {out }, x^{\prime}}+P_{x}+E_{x}+W_{x}\right](\mathrm{MGPY})$

Unknown water loss in plant,

$L=\sum_{x} I_{x}-\left[\sum_{x} P_{x}+\sum_{x} E_{x}+\sum_{x} W_{x}\right](\mathrm{MGPY})$ 
The calibration consists of an assessment of the closure of the water mass balance at the subsystem and system (facility) level. Failure to match inflows to outflows signify the presence of unknown losses or unaccounted for flows. For each subsystem, the estimated inflows are compared against estimated outflows (Figure 3a) to assess the presence of unknown losses. Subsequently, the estimates for every subsystem are aggregated and compared with the plant-level utility bills or metered data for self-supplied water (Figure 3b) to calibrate the model. Discrepancies between the two sources of information indicate the need for reviewing calculations or investigating unaccounted for flows. The user is prompted to inspect potential unaccounted flows and manually add or correct flows as necessary. In cases where metered data is not available, the estimates from Section 2.2.1 are considered the most accurate information available. However, facilities are encouraged to collect information and not rely completely on estimations for their water accounting.

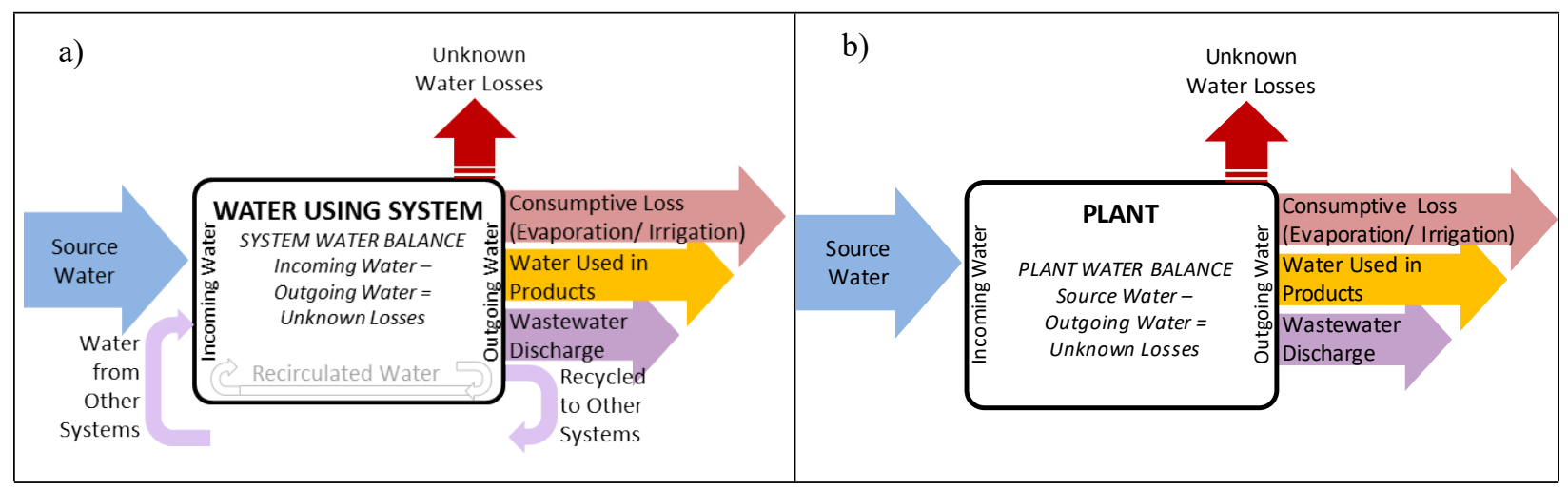

Figure 3. Panel a): Water balance for a subsystem. Panel b): water balance for the whole facility.

\subsubsection{True Cost of Water Calculations}

Once the water flow model is established and balanced, the cost components of the true cost of water are estimated. The specific variables and calculations to estimate the true cost are described in Table 7. The accounted components of the true cost are estimated in five steps as follows.

1. Volumes of water intake and wastewater discharge for every subsystem are calculated based on fractions of water use and discharge and system (facility) total water intake and discharge.

2. Volumes of water (intake or recirculated) and wastewater for every subsystem treated by each treatment process are calculated based on volumes of water used and wastewater discharged by each subsystem and the fractions of water that each treatment process $t$ treats for the specific subsystem $x$.

3. Operational variables of pumps and motors, such as motor capacity, efficiency, and hours of operation, are used to estimate the energy used.

4. The fuel consumption associated with the heat energy in wastewater is computed using the average temperature of source water intake and wastewater discharge, the temperature rise, as well as water properties and heating fuel efficiency.

5. The true cost of water is computed by the sum of the products of water or energy embedded and the corresponding unit cost of each component of the true cost as follows.

- The water intake and wastewater volumes $\left(I_{x, s}\right.$ and $W_{x, o}$ from Step 1) are multiplied by the unit cost of water intake from and wastewater disposal to municipal services. 
- The volumes of water and wastewater treated $\left(T_{x, t}\right.$ and $T_{x, t}{ }^{\prime}$, from Step 2) multiplied by a lumpsum unit cost of treatment is entered that combines the costs of chemicals, pumping energy, maintenance, and annualized cost of equipment installation.

- The energy used for pumps and motors $\left(\right.$ Elec $_{x}$ from Step 3$)$ is multiplied by the unit cost of electricity.

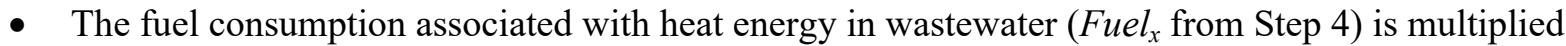
by unit cost of fuel.

Table 7. The five-step methodology to estimate the true cost of water.

\begin{tabular}{ll}
\hline & User Inputs \\
\hline $1 \quad$ Subsystem Water Intake and Wastewater Discharg \\
& $\mathrm{f}_{\mathrm{x}}\left(I_{x, s}\right):$ Fraction of Water Intake by Source \\
& $\mathrm{f}_{\mathrm{x}}\left(W_{x, o}\right)$ : Fraction of Wastewater \\
& Discharge by Outlet
\end{tabular}

\section{Calculations}

Water Intake by Subsystem $x$ from Source s,

$I_{x, s}=\mathrm{f}_{\mathrm{x}}\left(I_{x, s}\right) * I_{x}$, such that $\sum_{x} I_{x, s} \approx I_{s}$

Wastewater Discharge from Subsystem $x$ to Outlet $o$,

$W_{x, o}=\mathrm{f}_{\mathrm{x}}\left(W_{x, o}\right) * W_{x}$, such that $\sum_{x} W_{x, o} \approx W_{o}$

\section{Water and Wastewater Treatment}

$\mathrm{f}_{\mathrm{x}}\left(I_{x, s, t}\right), \mathrm{f}_{\mathrm{x}}\left(R_{i n, x, t}\right), \mathrm{f}_{\mathrm{x}}\left(R_{i n, x^{\prime}, t}\right)$ : Fraction of Intake and Recirculated Water associated with

Subsystem $x$ that undergoes Treatment Process $t$

$\mathrm{f}_{\mathrm{x}}\left(\mathrm{W}_{\mathrm{x}, 0, \mathrm{t}^{\prime}}\right)$ : Fraction of Wastewater from Subsystem

$x$ that undergoes Wastewater Treatment Process $t^{\prime}$

3 Pump and Motor Electricity Use

H: Hours of Operation per Year

kW or hp:Motor Capacity

$\eta:$ Motor Efficiency

V: Volts

A:Amperage

Pf:Power Factor

\section{Heat Energy in Wastewater}

$\mathrm{T}_{\mathrm{x}, \text { incoming: }}$ Average Temperature of Intake Water $\left({ }^{\circ} \mathrm{F}\right)$

$\mathrm{T}_{\mathrm{x}, \text { wastewater: Average Temperature }}$ of Wastewater $\left({ }^{\circ} \mathrm{F}\right)$

$\eta$ : Heating Fuel Efficiency

$\rho$ : Density of Water (lb/gal)

$\mathrm{C}_{\mathrm{p}}$ :Specific Heat of Water $\left(\mathrm{Btu} / \mathrm{lb} \cdot{ }^{\circ} \mathrm{F}\right)$
Subsystem Water Treated by Process $t$,

$T_{x, t}=\sum_{\mathrm{s}}\left\{\mathrm{f}_{\mathrm{x}}\left(I_{x, s, t}\right) * I_{x, s}\right\}+\left\{\mathrm{f}_{\mathrm{x}}\left(R_{i n, x, t}\right) * R_{\text {in, } x}\right\}+\sum_{\mathrm{x}}\left\{\mathrm{f}_{\mathrm{x}}\left(R_{i n, x^{\prime}, t}\right)\right.$

Wastewater Treated by Process $t$,

$\mathrm{T}_{\mathrm{x}, \mathrm{t}}^{\prime}=\sum_{\mathrm{o}}\left\{\mathrm{f}_{\mathrm{x}}\left(W_{x, o, t}\right) * W_{x, o}\right\}$

Pump or Motor Electricity Consumtion for Subsystem $x$,

Elec $_{x}(\mathrm{kWh} /$ year $)=\sum_{\text {all pumps } / \text { motors }}\left\{\begin{array}{r}\left(\frac{V * A}{100}\right) * P f * H \text {, for singl } \\ \left(\frac{V * A}{1000} * 1.732\right) * P f * H \text {, for } 1\end{array}\right.$

Fuel Consumption Associated with Heat Energy in Wastewater Discharged by Subsystem $x$ (MMBtu/year),

Fuel $_{x}=\rho * W_{x} * C_{p} *\left(T_{x, \text { incoming }}-T_{x, \text { wastewater }}\right) / \eta$ 
Table 7. The five-step methodology to estimate the true cost of water (continued).

5 True cost of water

$\$_{\mathrm{S}}$ : Unit Cost of Water Intake from Source $s$

True Cost of Water for Subsystem $x$,

$\$_{0}$ : Unit Cost of Wastewater Discharge to Outlet $o$

$\$_{\mathrm{t}}$ : Unit Cost of Water Treatment $t$

$\$_{x}=\sum_{\mathrm{s}}\left(\$_{S} * I_{x, s}\right)+\sum_{\mathrm{o}}\left(\$_{o} * W_{x, o}\right)+\sum_{\mathrm{t}}\left(\$_{t} * \mathrm{~T}_{\mathrm{x}, \mathrm{t}}\right)+$

$\$_{\mathrm{t}}$ : Unit Cost of Wastewater Treatment $t^{\prime}$

$\$_{\text {elec }}$ : Unit Cost of Electricity

$\$_{\text {fuel }}$ Unit Cost of Heating Fuel

\subsection{ADDITIONAL CAPABILITIES}

\subsubsection{Potential Water Savings Calculations}

Based on the water balance and estimates of the cost components of the true cost of water, PWP estimates the potential water and associated cost savings from eliminating losses and increasing recirculation rates (e.g., by increasing cycles of concentration for cooling towers and increasing cycles of concentration and condensate return for boilers), as shown in Table 8.

Table 7. Potential water savings calculations.

User Inputs Calculations

Cooling Tower: Increasing Cycle of Concentration

E: Evaporation Loss (MGPY)

Reduced Makeup Water, $M^{\prime}=E /\left(1-1 / C^{\prime}\right)$ (MGPY)

$C^{\prime}$ : Cycles of Concentration

Makeup Water Savings, $\Delta M=M_{\text {baseline }}-M^{\prime}$ (MGPY)

Maseline: Baseline Makeup Water (MGPY)

Boiler: Increasing Cycle of Concentration and Condensate Return

$\mathrm{M}_{\text {baseline: }}$ : Baseline Makeup Water (MGPY)

Reduced Gross Water Use, $G^{\prime}=\left[e /\left(1-1 / C^{\prime}\right)\right] * B H P * L$

H: Hours of Operation per Year

* $0.002 * H * 60 / 10^{6}$ (MGPY)

BHP: Boiler Horsepower

Reduced Makeup Water, $M^{\prime}=\left(1-\% \mathrm{R}^{\prime} / 100\right) * G^{\prime}$ (MGPY)

L:Load as a Fraction of Boiler Horsepower

Makeup Water Savings, $\Delta M=M_{\text {baseline }}-M^{\prime}$ (MGPY)

e: Steam Generation Rate (lb/h) per BHP

$C^{\prime}$ : Increased Cycles of Concentration

$\% \mathrm{R}^{\prime}$ :Increased Condensate Return (\%)

\subsubsection{Comparison with Industry Average}

Once a calibrated water flow model is established, normalized indicators to characterize the water use and true cost of water (i.e., per production unit or per production-unit cost) are determined. These indicators are compared with the industry average water data sets, which are obtained from two sources: the EIOLCA (Economic Input-Output Life Cycle Assessment) (Carnegie Mellon University Green Design Institute, 2018) and the Statistics Canada (STATCAN) database (Statistics Canada, 2018). EIO-LCA estimates the materials and energy resources required and the environmental externalities resulting from several interlinked activities in the economy. PWP uses the water withdrawal data from the EIO-LCA 
database to create a benchmark for source water intake by a given manufacturing plant within its North American Industry Classification System (NAICS) code. The STATCAN database, based on the Industrial Water Survey conducted every 2 years, provides information on the intake, costs, sources, treatments, and discharge of water used by the industrial sector within Canada. PWP uses the averages and coefficients of variance of water use requested from STATCAN ${ }^{2}$ to allow facilities to compare their water intake, gross water use (including water intake and recirculation), and discharge flow with those of peers within similar NAICS codes. This process helps facilities determine how much focus should be placed on water savings measures.

\subsubsection{Evaluation of Plant Water Efficiency Status}

PWP includes a set of questions about the presence of plant and subsystem-specific water efficiency measures. These questions were formulated based on industry best practices, guides, and publications (New Mexico Office of the State Engineer, 1999; Seneviratne, 2006; Trueblood, Chow, Ritchie, \& Ganji, 2015; U.S. EPA, 2011) and can help plant management determine the next steps in implementing water efficiency measures, including management, considering alternative sources, minimizing losses, recirculation, and reuse. Sample questions regarding plant water management and cooling and condensing subsystem are included in Table 9.

Table 8. Example plant and subsystem water efficiency status evaluation questionnaire.

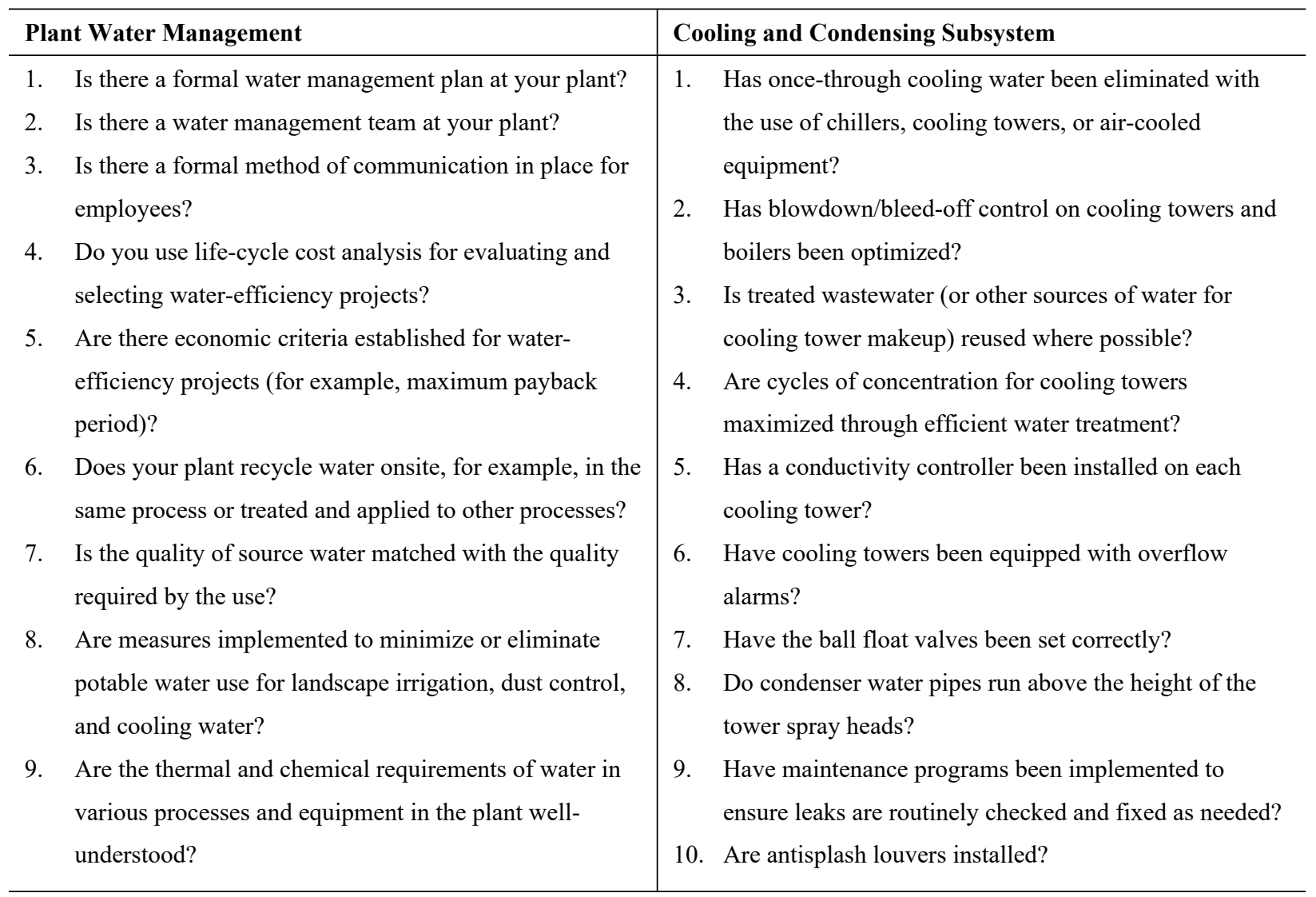

${ }^{2}$ Rao et al. (2017) outlines the similarities and differences between the economies of the United States and Canada and uses Canadian water use data normalized by employment data to make detailed estimates of US manufacturing water use. For PWP, no such adjustments are made. 


\begin{tabular}{|c|c|}
\hline Plant Water Management & Cooling and Condensing Subsystem \\
\hline $\begin{array}{l}\text { 10. Are measures implemented to conserve water by } \\
\text { reducing water use? }\end{array}$ & $\begin{array}{l}\text { 11. Are drift eliminators inspected and assessed by a } \\
\text { specialist? }\end{array}$ \\
\hline $\begin{array}{l}\text { 11. Are measures implemented to conserve both water and } \\
\text { energy, for example, recycling warm water rather than } \\
\text { heating intake water? }\end{array}$ & $\begin{array}{l}\text { 12. Have flow meters been installed on makeup and } \\
\text { blowdown lines? } \\
\text { 13. Are conductivity meters installed on blowdown lines? }\end{array}$ \\
\hline $\begin{array}{l}\text { 12. Are measures implemented to reduce wastewater as well } \\
\text { as toxic waste disposal? }\end{array}$ & $\begin{array}{l}\text { 14. Are blowdown lines operated in continuous mode? } \\
\text { 15. Has side stream filtration been installed? }\end{array}$ \\
\hline $\begin{array}{l}\text { 13. Do water and wastewater utilities provide rebates and } \\
\text { other financial assistance for implementing water } \\
\text { conservation measures? }\end{array}$ & $\begin{array}{l}\text { 16. Has an automatic shutdown unit been installed for the } \\
\text { unit? } \\
\text { 17. Has sulfuric acid been added to adjust } \mathrm{pH} \text { ? }\end{array}$ \\
\hline $\begin{array}{l}\text { 14. Does your plant pay or have justification to request for } \\
\text { reduced wastewater utility rates? }\end{array}$ & 18. Are high-efficiency drift eliminators in use? \\
\hline
\end{tabular}

\subsubsection{Evaluation of Water-Savings Priorities}

PWP helps determine gross water use, quantify unknown losses, and determine the true cost of water for different water-using subsystems in a plant. This helps the user identify subsystems and water flows that are contributing the most to source water intake or the true cost of water and need the most attention, as shown in Figure 4. Accordingly, the user may prioritize measures to align with the company's priority for water savings versus cost savings.

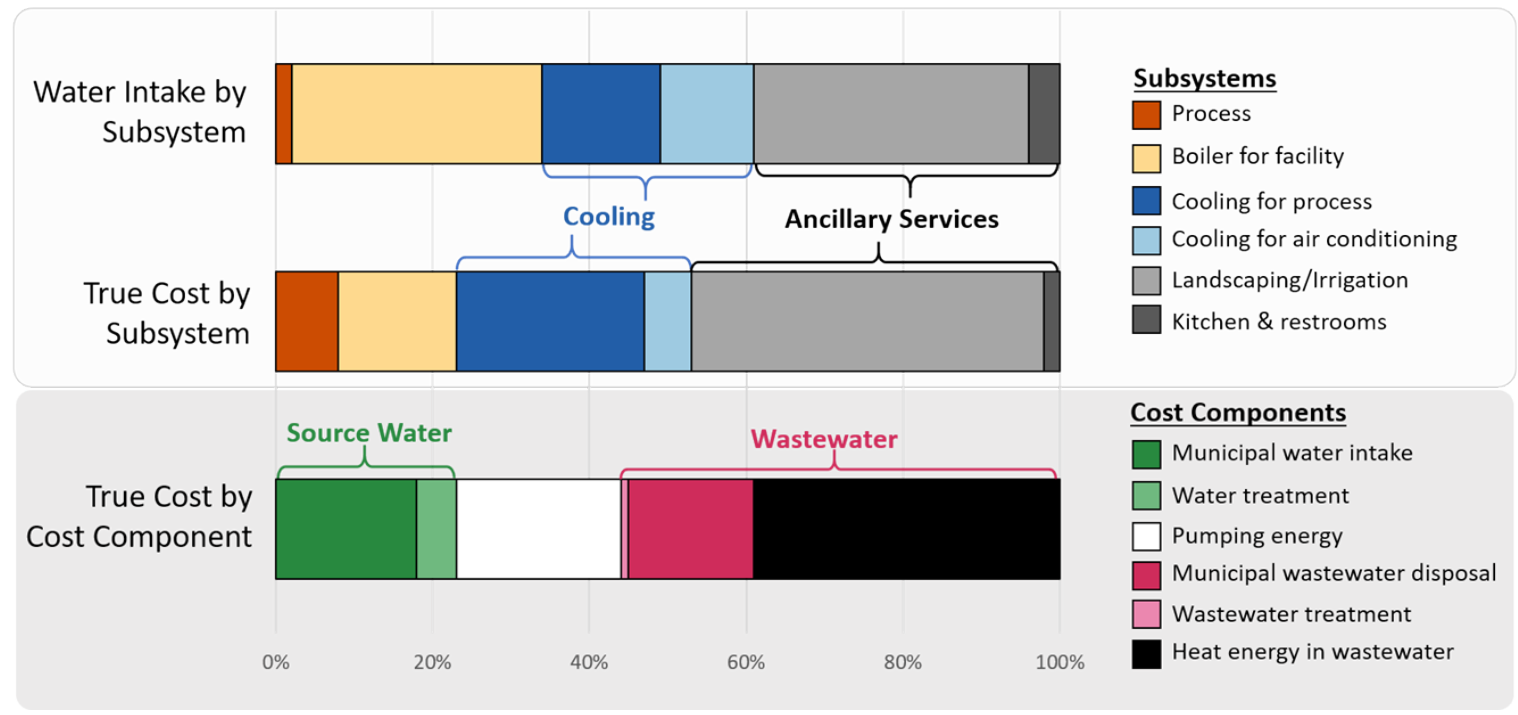

Figure 4. Example of breakdown and comparison of source water intake and true cost.

Measures for water savings would typically include considering alternative process-related methods requiring less water; installation of water efficiency measures; reuse; recycling; minimizing leaks; and water and wastewater treatment to reduce the need for makeup water. Measures for cost savings can additionally include those that may not reduce water use, such considering alternative sources of water, onsite wastewater disposal, and energy-saving measures associated with water using subsystems. The tool 
may help identifying cost-saving, water-saving, or energy-saving measures independently. Such measures may be conflicting, for instance in the case when water-saving measures imply more water treatment and recirculation, which may lead to higher cost and energy use. The selection of sustainability measures needs to be evaluated by the facility according to their goals. 


\section{IMPLEMENTATION OF PLANT WATER PROFILER TOOL}

Through DOE's Advanced Manufacturing Office (AMO), ORNL offers support to Better Plants program participants through Water In-Plant Training (Water INPLT) in the form of multi-day workshops performed by industry-recognized experts. The Water INPLT program was developed in line with the INPLT model by Alkadi, Nimbalkar, Fontaine, \& Schoeneborn (2013) that includes both classroom and field-based sessions and trains attendees to identify water-saving opportunities, estimate savings, and implement projects (Guo, Wenning, Nimbalkar, Travis, \& Levine, 2019). Three pilot trainings have been conducted during the second half of 2019. During these trainings, the PWP tool was used as the core analysis tool for plant water use assessment and true cost calculation. The facilities that benefited from the INPLT were one iron and steel manufacturing plant, one fiberglass manufacturing plant, and one vinyl siding manufacturing plant. The trainings were accompanied by facility inspections in the modality of "treasure hunts," in which cross-functional teams of employees engaged in the process of identifying operational and maintenance water efficiency improvements. The following sections (3.1 to 3.3) describe for each facility the general water uses, the information that PWP tool can provide at the subsystem disaggregation level, best practices, opportunities identified, and common challenges encountered.

\subsection{IRON AND STEEL MANUFACTURING FACILITY}

The first pilot Water INPLT training was conducted at an iron and steel manufacturing plant. Due to the large size of the plant, only the cold mill was considered as a feasible plant boundary to analyze during the 2.5-day event. Figure 5 shows the water flows identified across the system boundaries in the cold mill. The main water-using subsystems in the cold mill included processes - a hot dip galvanizing line (HDGL), tandem mill and anneal, and pickle line - two cooling towers subsystems, and a kitchen and restrooms. The source water intake is municipal water, and wastewater disposal (after treatment) is into a river. The water intake to the HDGL is treated by a reverse osmosis (RO) system before use. The wastewater from the processes is treated by an oily wastewater treatment system and a metal removal system before being discharged to the river. The blowdown from cooling towers is directed to a lagoon in the facility boundary that serves as a water recycle system for other parts of the facility. 


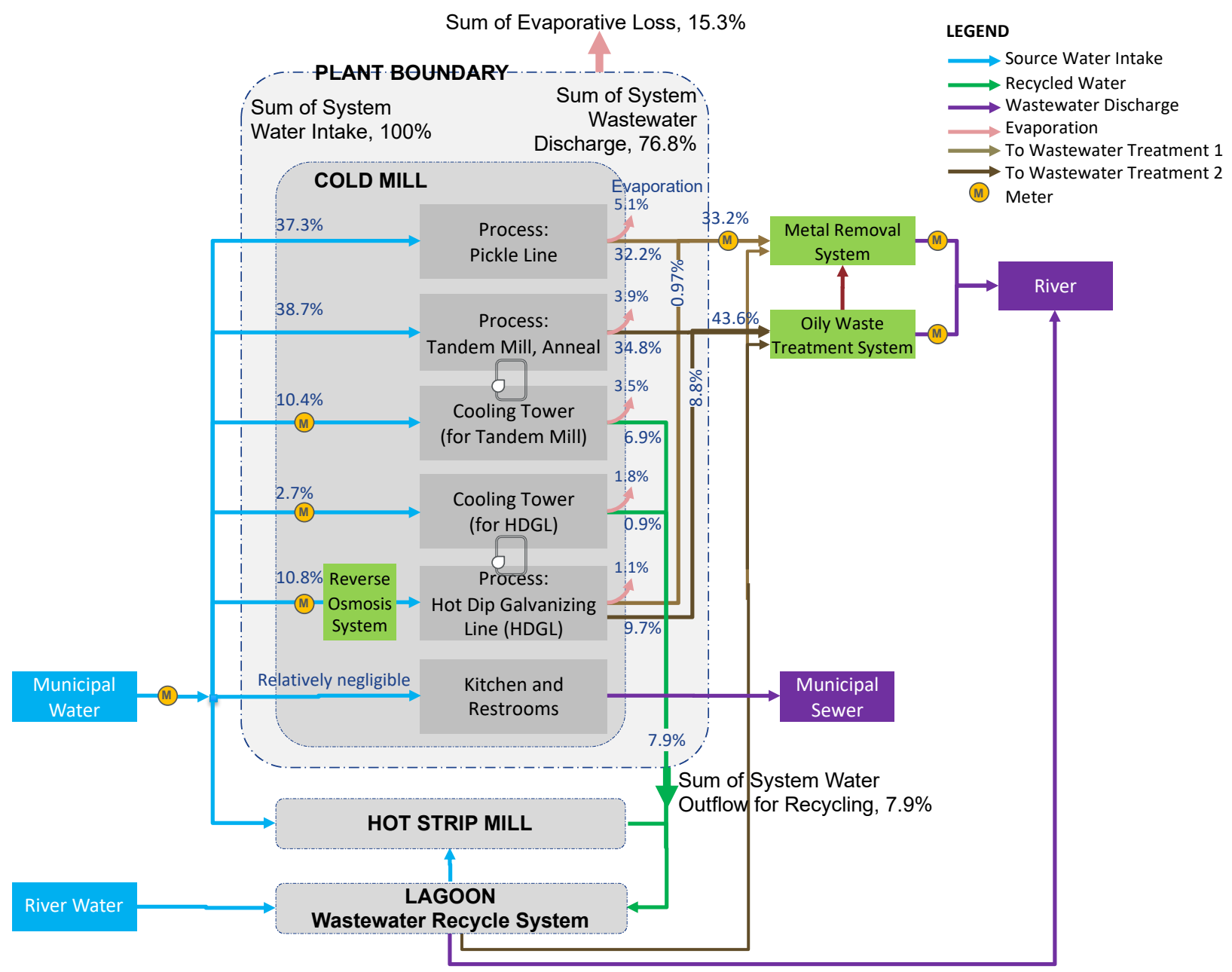

Figure 5. Water flow diagram for the cold mill of an iron and steel manufacturing plant.

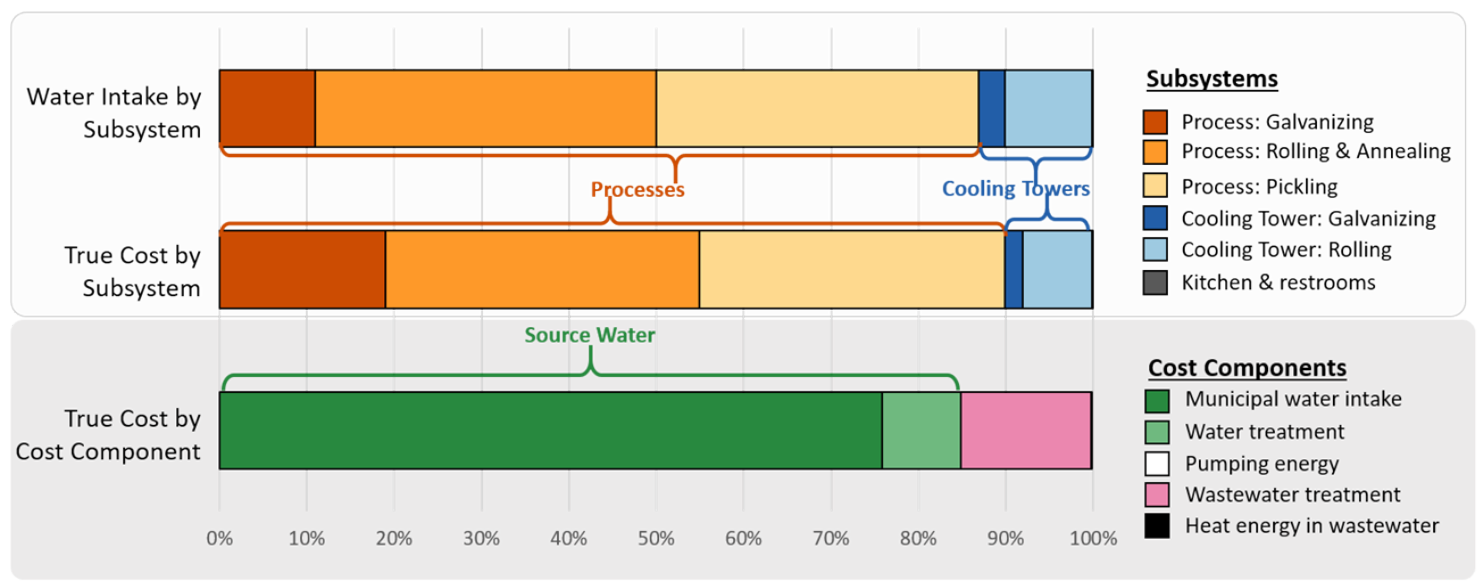

Figure 6 shows the breakdown of source water intake and the true cost of water by subsystems and cost component in the cold mill, as well as the true cost by cost component. Both pickle line and the tandem mill and anneal contribute about $35-40 \%$ toward source water intake as well as the true cost of water. 
HDGL uses $11 \%$ of source water intake but accounts for $19 \%$ of the true cost of water.

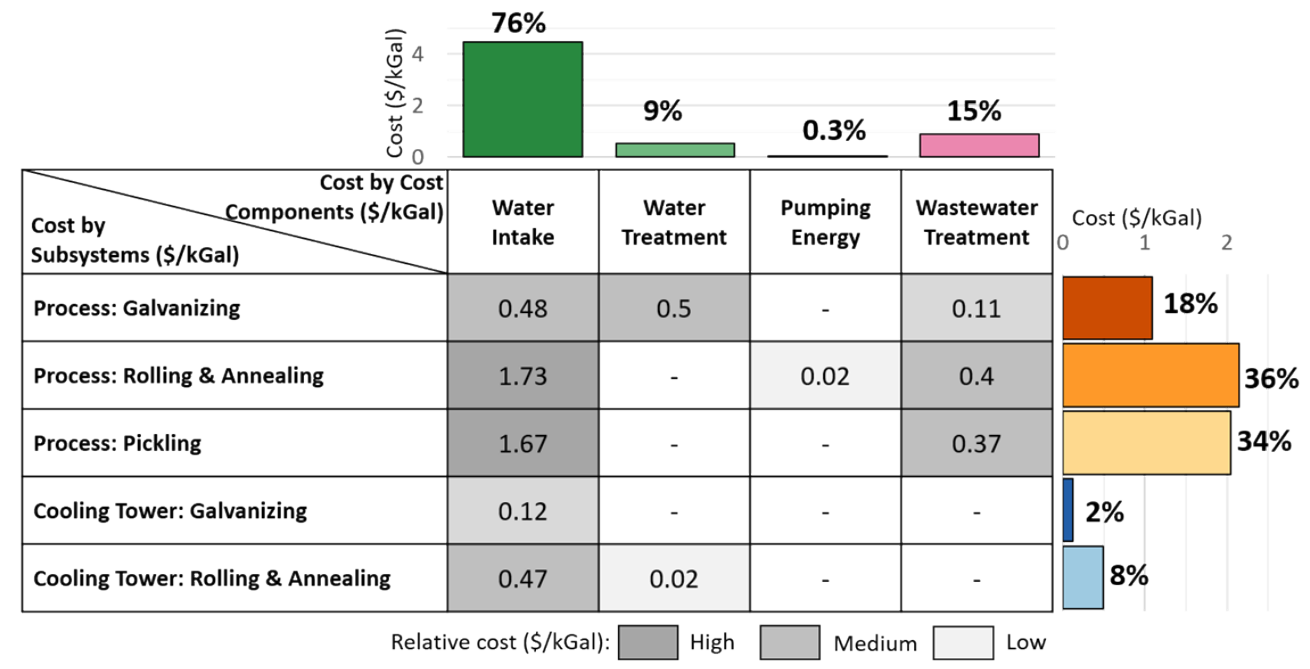

Figure 7 shows the true cost of water by subsystem and cost components. The true cost components were $76 \%$ for municipal water intake, $15 \%$ for wastewater treatment, and $9 \%$ for water treatment.

Considering only the subsystem-level water flows, the cold mill used 0.12 thousand gallons per million metric ton of production and the true cost of water was $\$ 5.88$ per thousand gallons, which was 1.32 times the direct cost of water that the facility is billed.

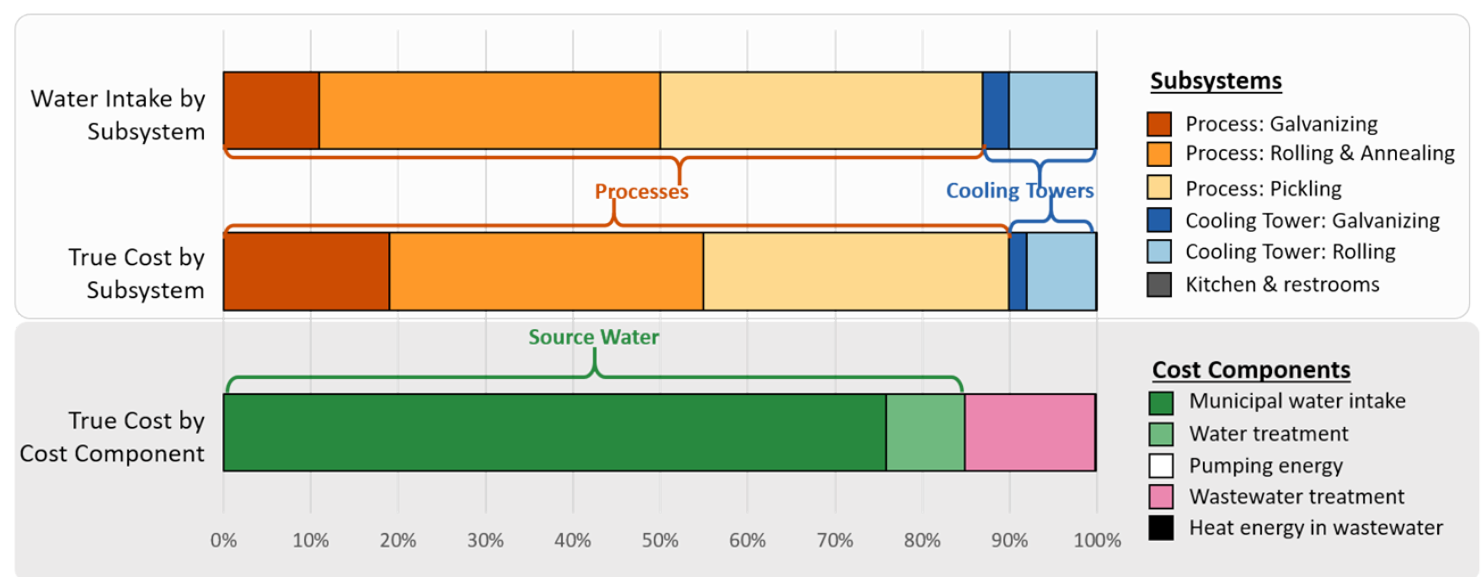

Figure 6. Water use and true cost by subsystem and cost component for the iron and steel manufacturing plant. 


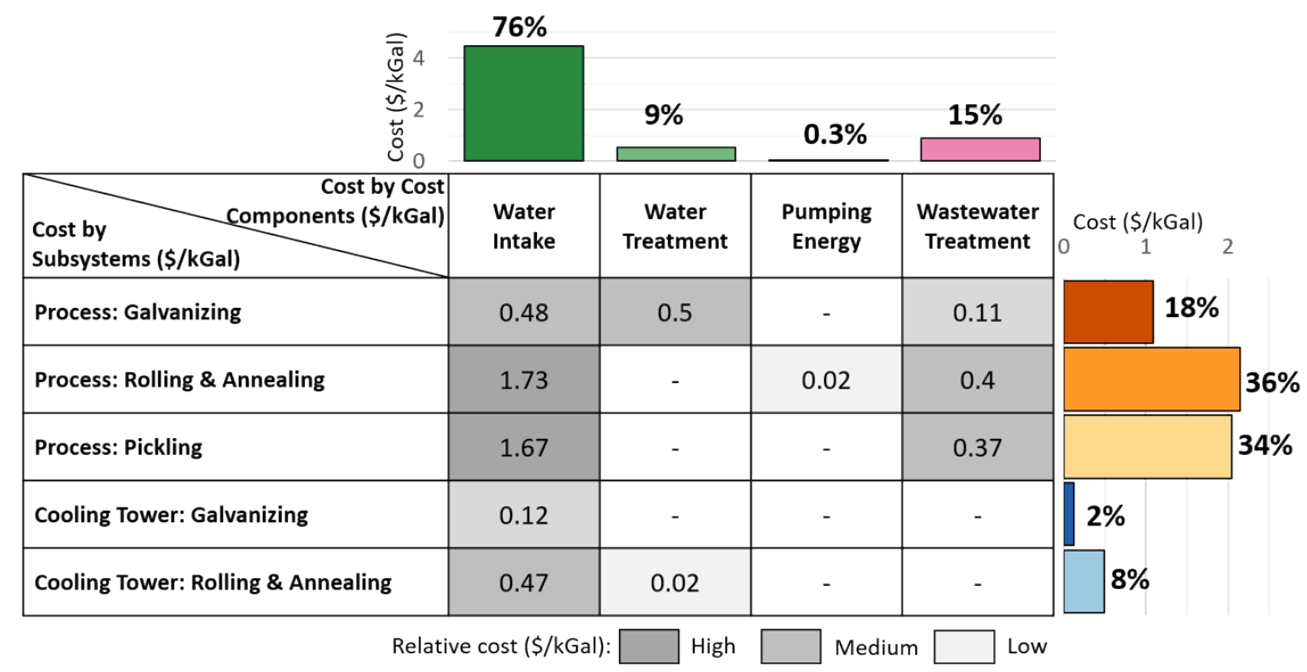

Figure 7. True cost of water by subsystem (rows) and by cost components (columns) for the cold mill of the iron and steel manufacturing plant.

The PWP exercise helped the facility identify water-intensive and cost-intensive subsystems at the facility. Based on this, appropriate areas were chosen for optimization and teams were put together to investigate the relevant water end users. The teams identified opportunities for water savings, and with the subsystem-level water flows determined using the PWP tool, the water and true cost savings from implementing these measures was determined. The best practices being followed in these areas were also identified as part of this activity.

The use of flow meters was observed throughout the plant. However, metering a few additional key flows would help. The steam trap management and blowdown recovery were also among the best practices at this plant. The cold mill cooling tower needs investigation and corrective actions in terms of correctly accounting the makeup water. The rolling and annealing and the pickling processes were found to be the most cost-intensive subsystems per unit source water intake, which makes them a potential subsystem for implementing water efficiency measures for a higher return of investment.

The water savings opportunities identified in the cold mill area of the plant included enabling a conductivity-controlled water supply for the cold mill cooling tower, installing a drift eliminator in HDGL cooling tower, and eliminating condensate leaks. With the subsystem-level water flows determined using the PWP tool, the water and true cost savings from implementing these measures was determined.

\subsection{FIBERGLASS MANUFACTURING FACILITY}

The second pilot Water INPLT training was conducted in a fiberglass manufacturing plant. The water intake source is groundwater. The wastewater from the processes is discharged to an industrial sewer and a domestic sewer. The main water-using subsystems in this plant included processes/subprocesses (e.g., forming spray and binder roller, drain bushing and wash down, chiller and dehumidifier system), a cooling tower, general cleaning and fire protection, and kitchen and restrooms. The forming and binding process requires groundwater treated by reverse osmosis (RO), whereas most of the remaining waterusing subsystems require groundwater treated with bleach.

Figure 8 shows the water flows identified across the system boundaries. The water balance using the PWP tool identified subsystem-level and plant-level water imbalances. First, the sum of subsystem-level water 
intake and that of wastewater discharge were lower than plant-level metered water intake and wastewater discharge, respectively, indicative of unaccounted water use. Further, the plant total metered water intake exceeded the wastewater discharge plus the sum of known evaporative losses, pointing to unknown losses to be identified.

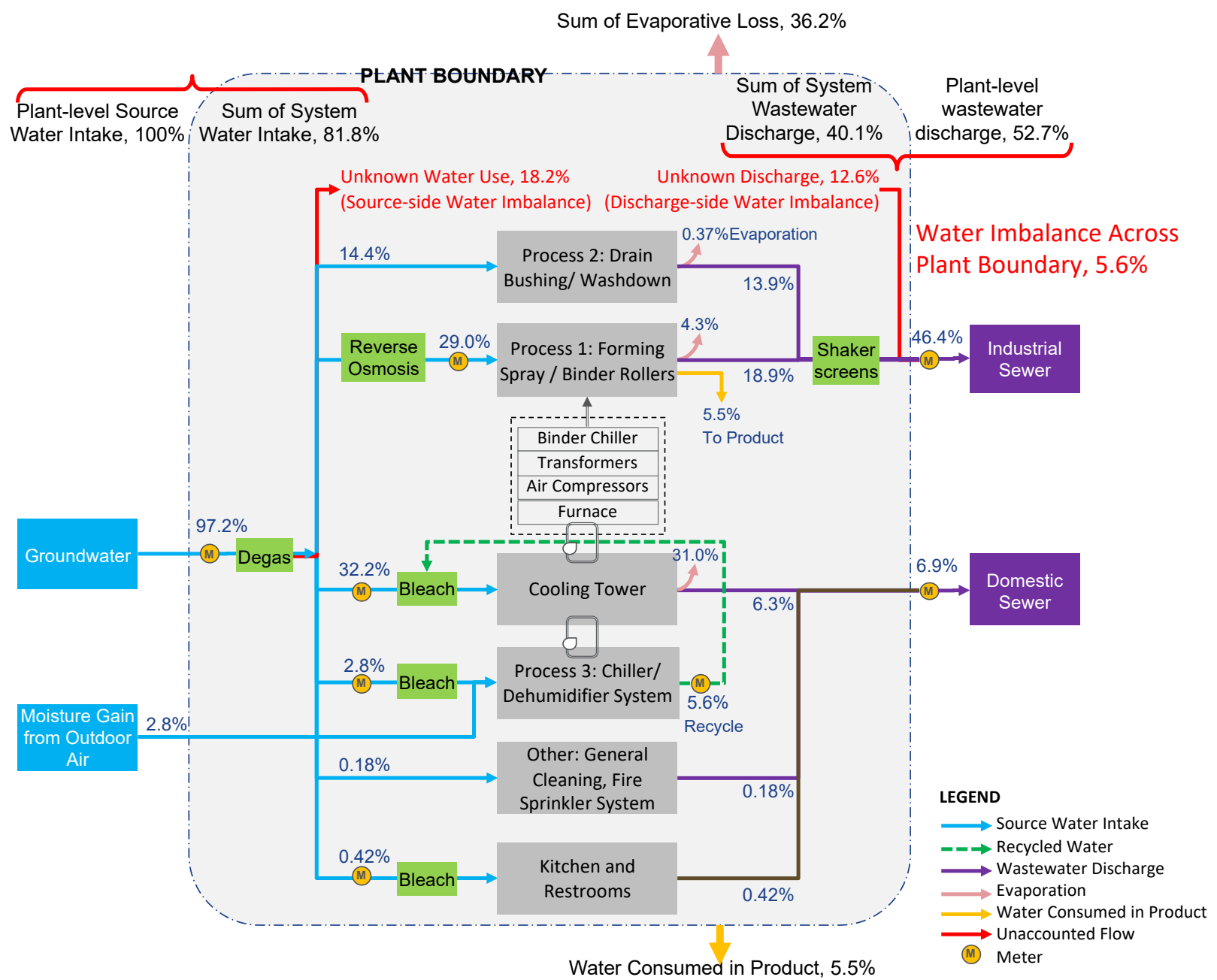

Figure 8. Water flow diagram for a fiberglass manufacturing plant (Pilot Training 2). 


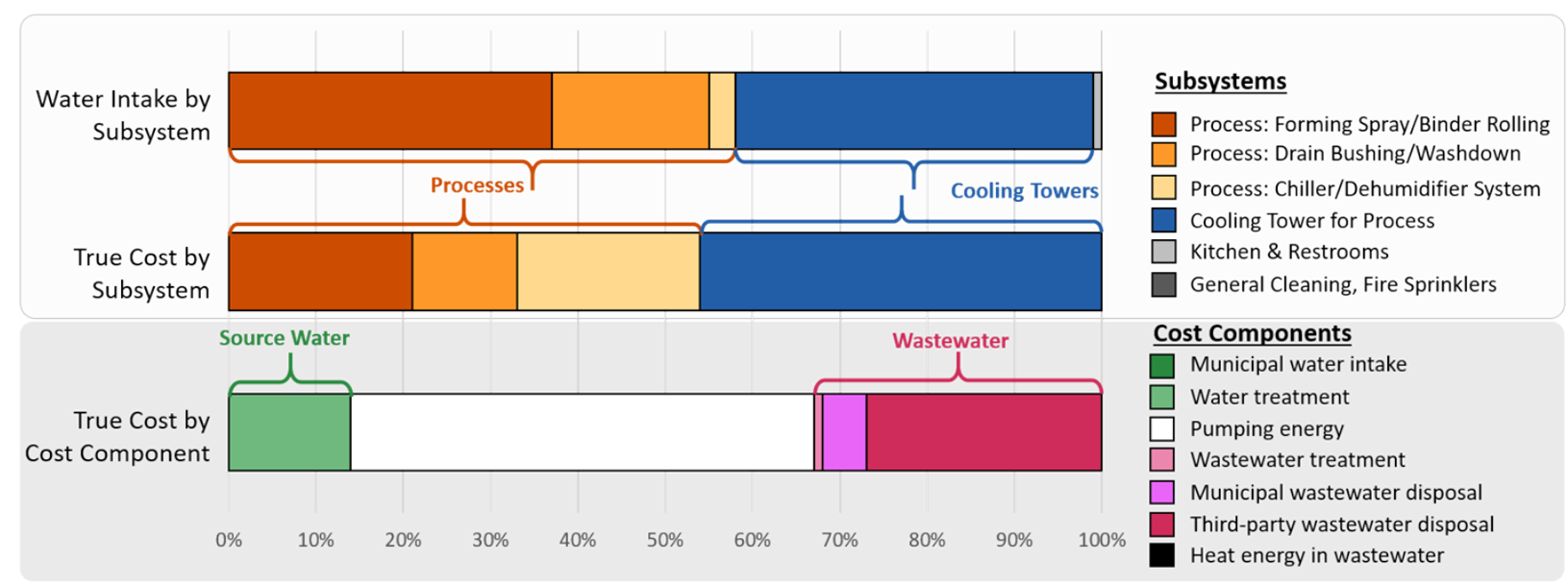

Figure 9 shows the breakdown of source water intake and the true cost of water by subsystems in the plant, as well as the true cost by cost component. The cooling tower contributed the most toward source water intake and the true cost of water $(41 \%$ and $46 \%$, respectively). The forming spray/binder roller accounted for $37 \%$ of source water intake and $21 \%$ of true cost of water, whereas the chiller/dehumidifier system with only $3 \%$ of source water intake contributed $21 \%$ toward the true cost of water.

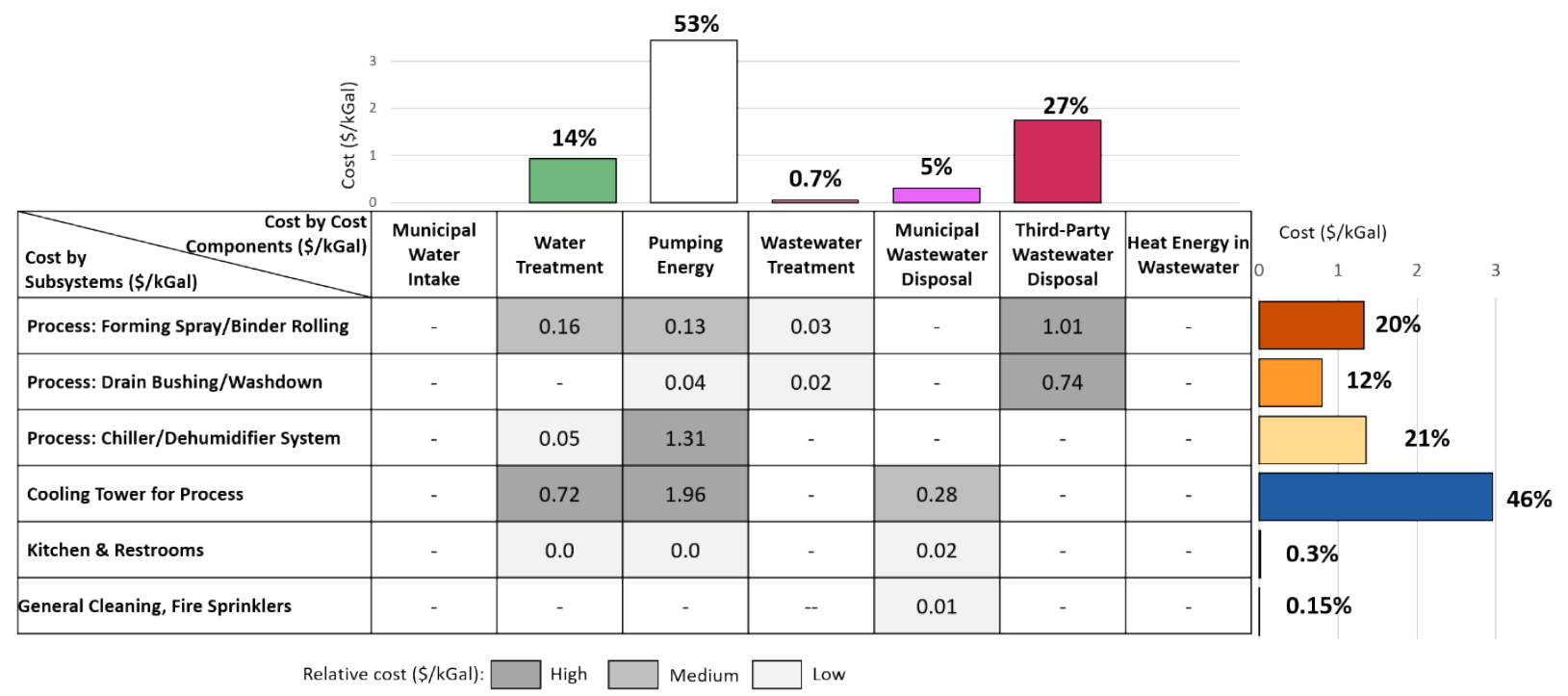

Figure 10 shows the true cost of water by subsystem and cost components. The largest true cost components were $53 \%$ for pump and motor energy followed by $27 \%$ for industrial wastewater discharge (marked as third-party disposal) and 14\% for water treatment. 


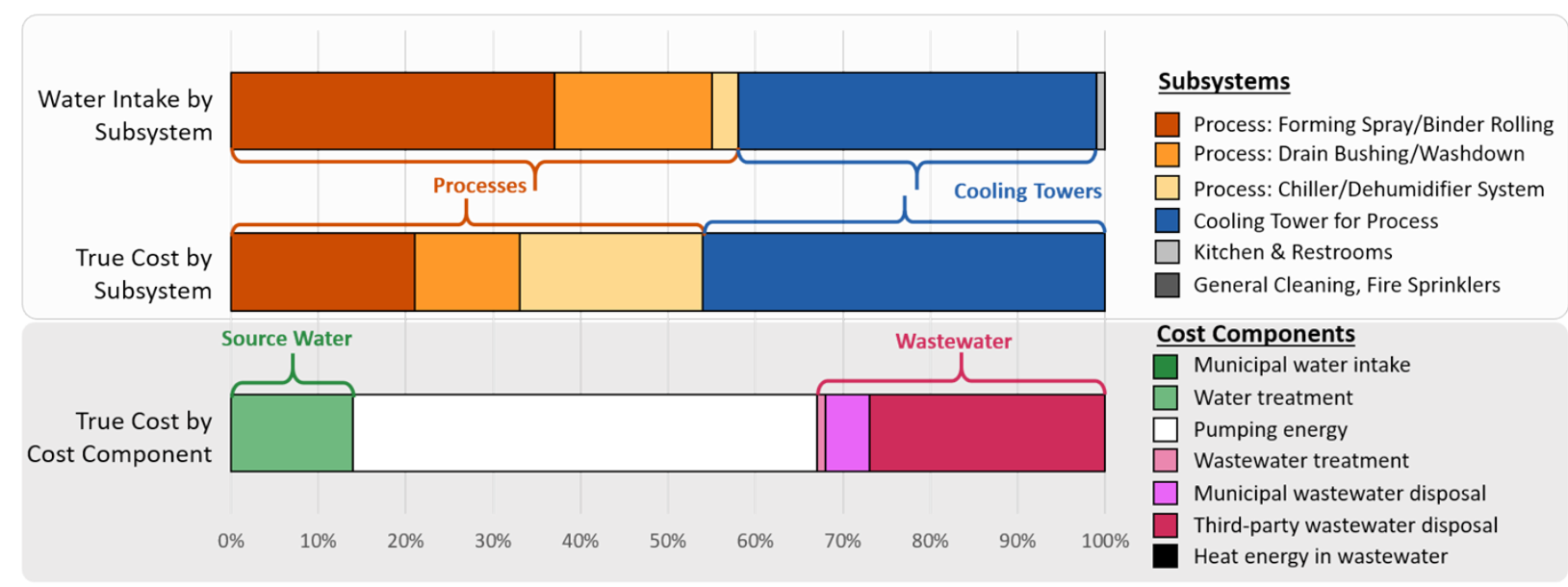

Figure 9. Water use and true cost by subsystem and cost component for the fiberglass manufacturing plant (Pilot Training 2).

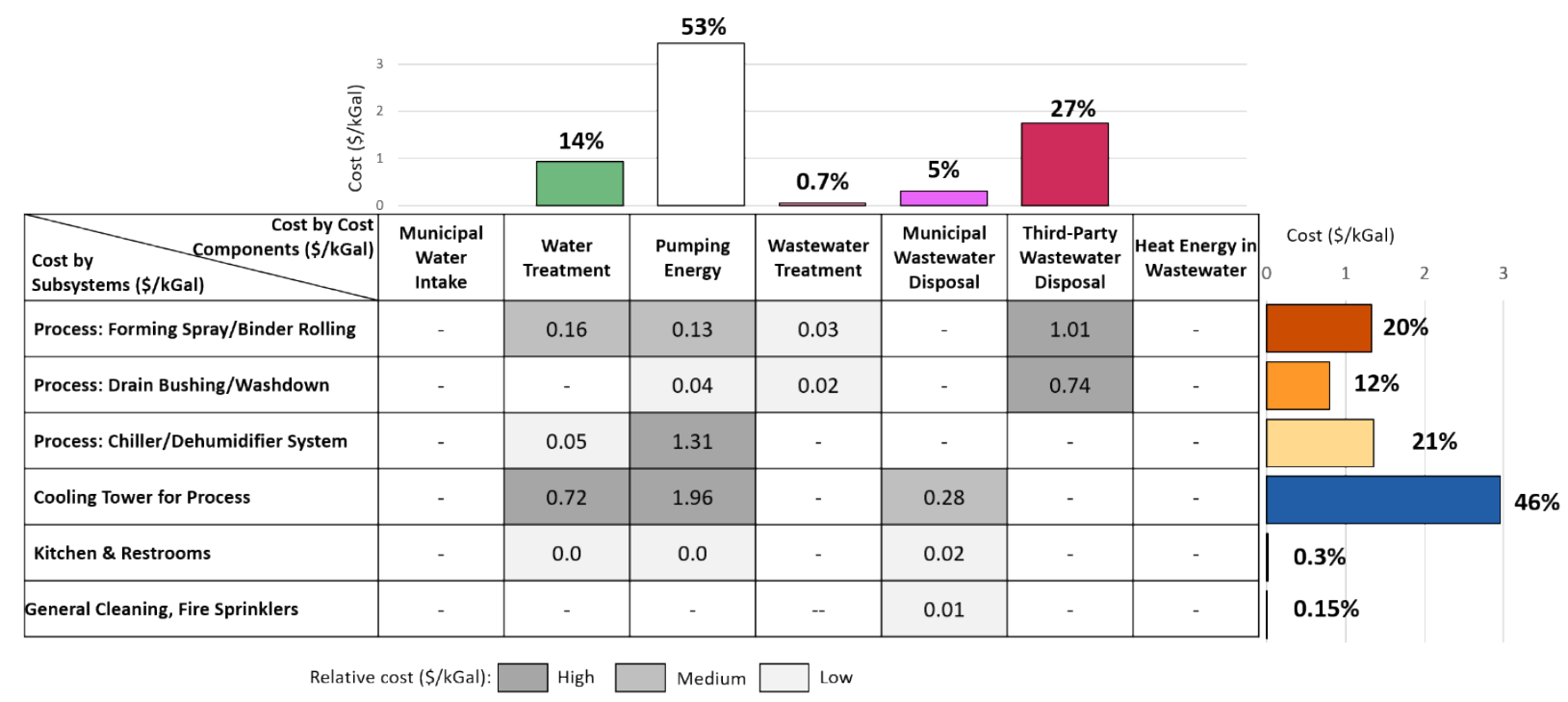

Figure 10. True cost of water by subsystem (rows) and by cost components (columns) for the fiberglass manufacturing plant (Pilot Training 2).

Considering only the subsystem-level water flows, the facility used 0.57 thousand gallons per metric ton of production, and the true cost of water was $\$ 6.48$ per thousand gallons, which was 3.15 times the direct cost of water that the facility sees on its bills.

The PWP exercise helped the facility identify water-intensive and cost-intensive subsystems at the facility. Based on this, appropriate areas were chosen for optimization and teams were put together to investigate the relevant water end users. The teams identified opportunities for water savings, and with the subsystem-level water flows determined using the PWP tool, the water and true cost savings from implementing these measures was determined. The best practices being followed in these areas were also identified as part of this activity. 
The use of submetering was observed in the plant. However, submetering additional flows to the process line would help break down and understand the water flows better. The recycling of water from the chiller/dehumidifier system for the cooling tower makeup water was among the best practices followed at this plant. The cooling tower was found to be one of the biggest uses of water and an efficiently operated subsystem. However, pumping energy and recirculation can be reduced with better controls. Awareness regarding the true cost of water can help reduce open blowing.

The water savings opportunities identified at this plant included correcting the water leaks, dehumidifier management according to the season that would result is reduced chiller load; chilled water system optimization by adding variable frequency drives (VFDs) to pumps; adjusting condenser water temperature, and chiller sequencing; and removing spray nozzle used in the production line that were found redundant/ineffective. With the subsystem-level water flows determined using the PWP tool, the water and true cost savings from implementing these measures was determined.

\subsection{PILOT TRAINING 3}

The third pilot Water INPLT training was conducted in a small size vinyl siding manufacturing plant. The source water intake is municipal water and the wastewater from the facility is discharged to a municipal sewer. The main water uses in this plant were for processes. The water intake in a cooling tower, process cooling loop, and quench tanks requires different water treatments.

Figure 11 shows the water flows identified across the system boundaries. The water balance using the PWP tool identified subsystem-level and plant-level water imbalances. First, the sum of subsystem-level water intake and that of wastewater discharge were slightly higher than plant-level metered water intake and wastewater discharge, respectively. Further, the plant total metered water intake exceeded the wastewater discharge plus the sum of known losses by 7\%, pointing to unknown losses to be identified.

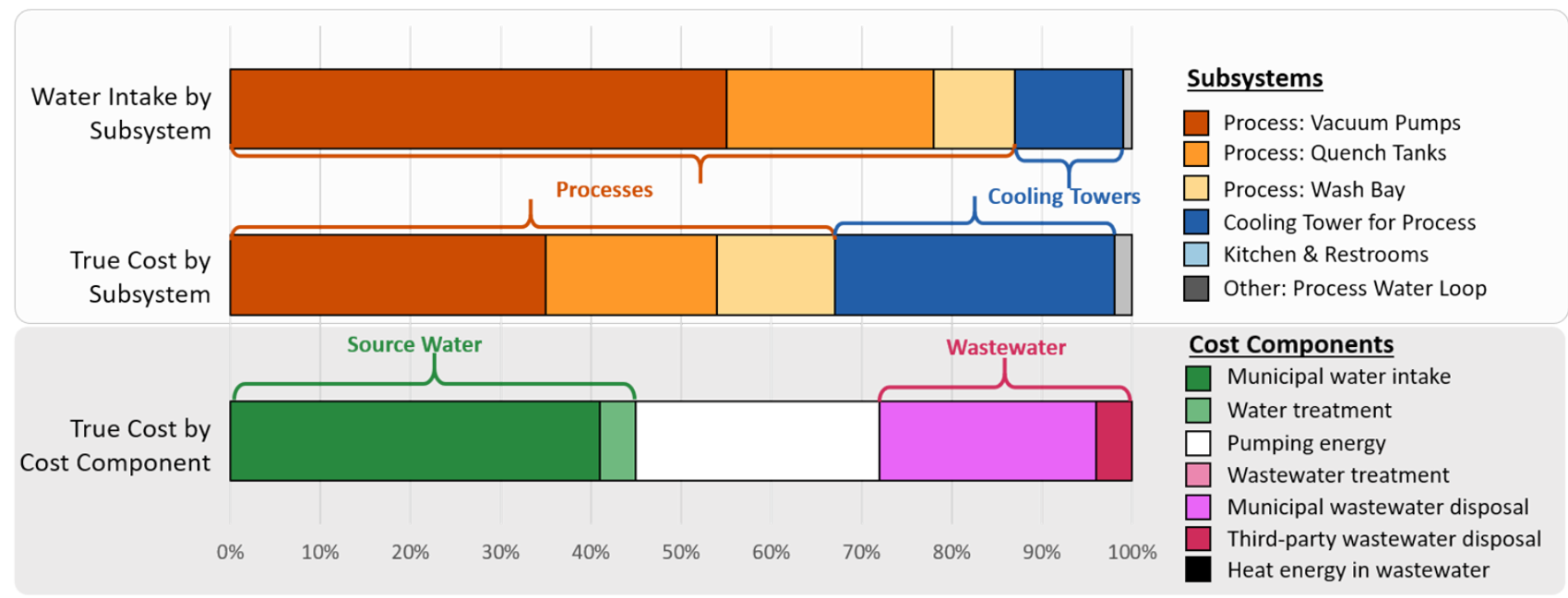

Figure 12 shows the breakdown of source water intake and the true cost of water by subsystems in the plant, as well as the true cost by cost component. The vacuum pumps contribute the most toward source water intake and the true cost of water (55\% and 35\%, respectively). The cooling tower subsystem with only $12 \%$ of source water intake contributed $31 \%$ toward the true cost of water. Quench tanks with $23 \%$ of source water intake contributed $19 \%$ toward the true cost of water. 


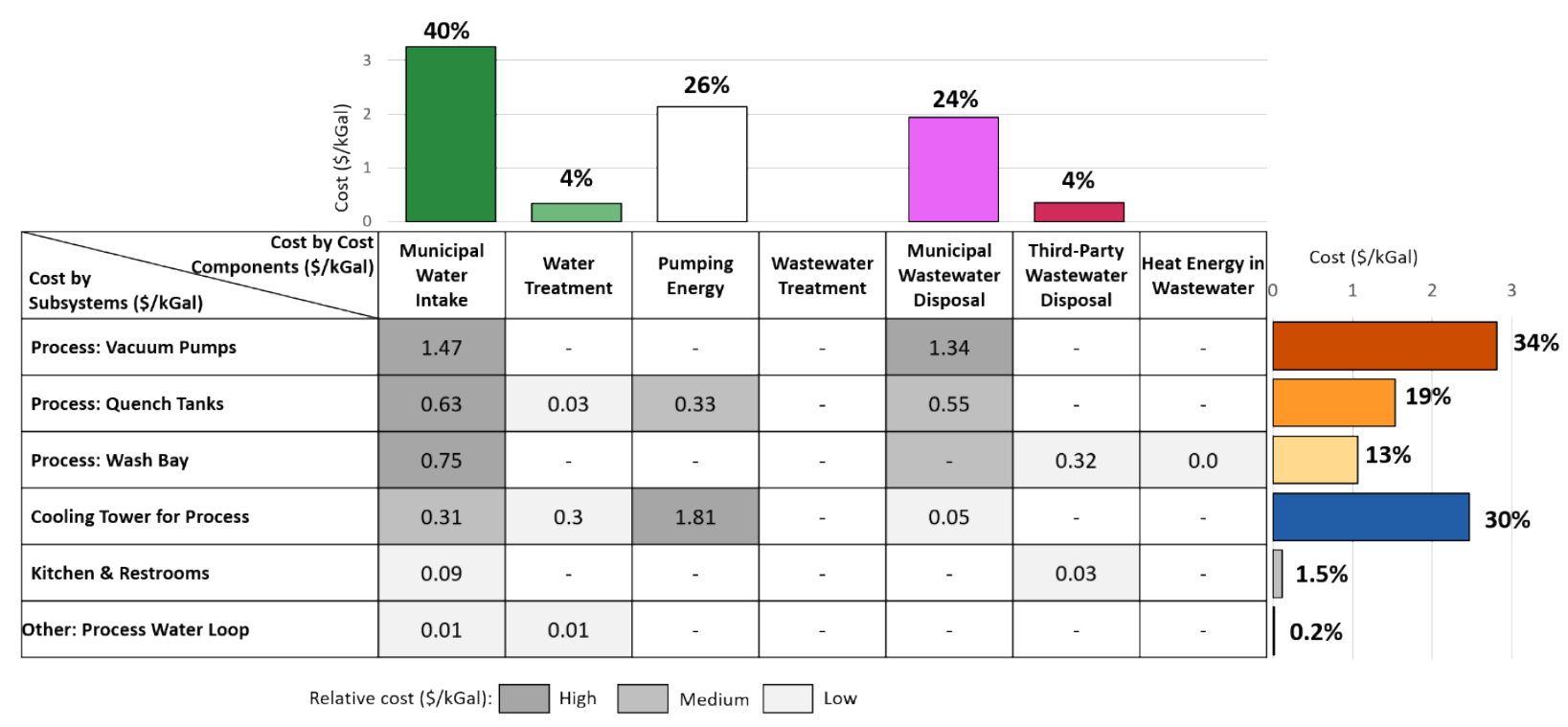

Figure 13 shows the true cost of water by subsystem and cost components. The largest true cost components were $40 \%$ for municipal water intake, $24 \%$ for municipal wastewater disposal, and $26 \%$ for pump and motor energy.

Considering only the subsystem-level water flows, the facility used 0.33 thousand gallons per $1000 \mathrm{lb}$ production and the true cost of water was $\$ 8.01$ per thousand gallons, which was 1.45 times the direct cost of water that the facility sees on its bills. 


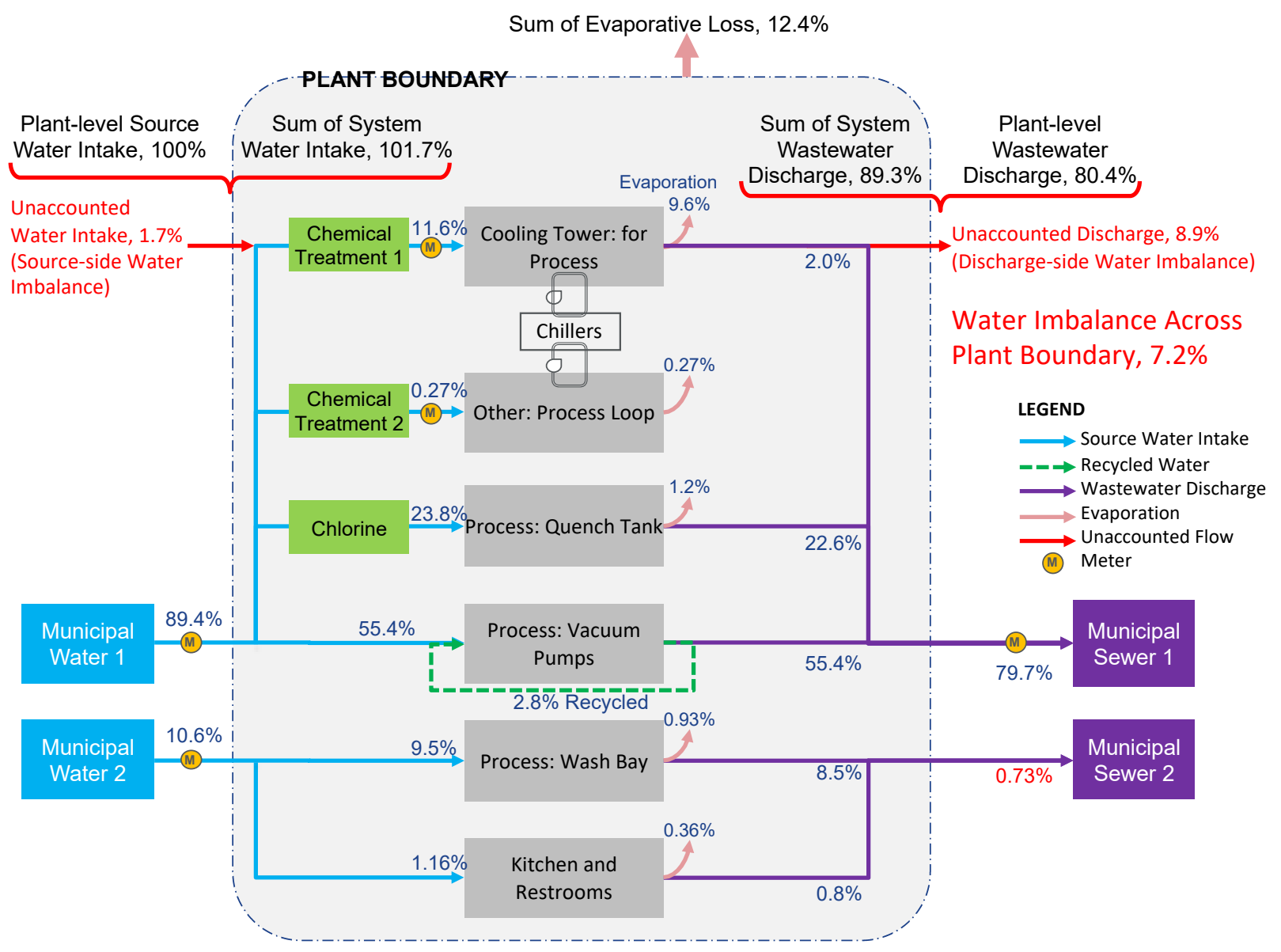

Figure 11. Water flow diagram for a vinyl siding manufacturing plant (Pilot Training 3).

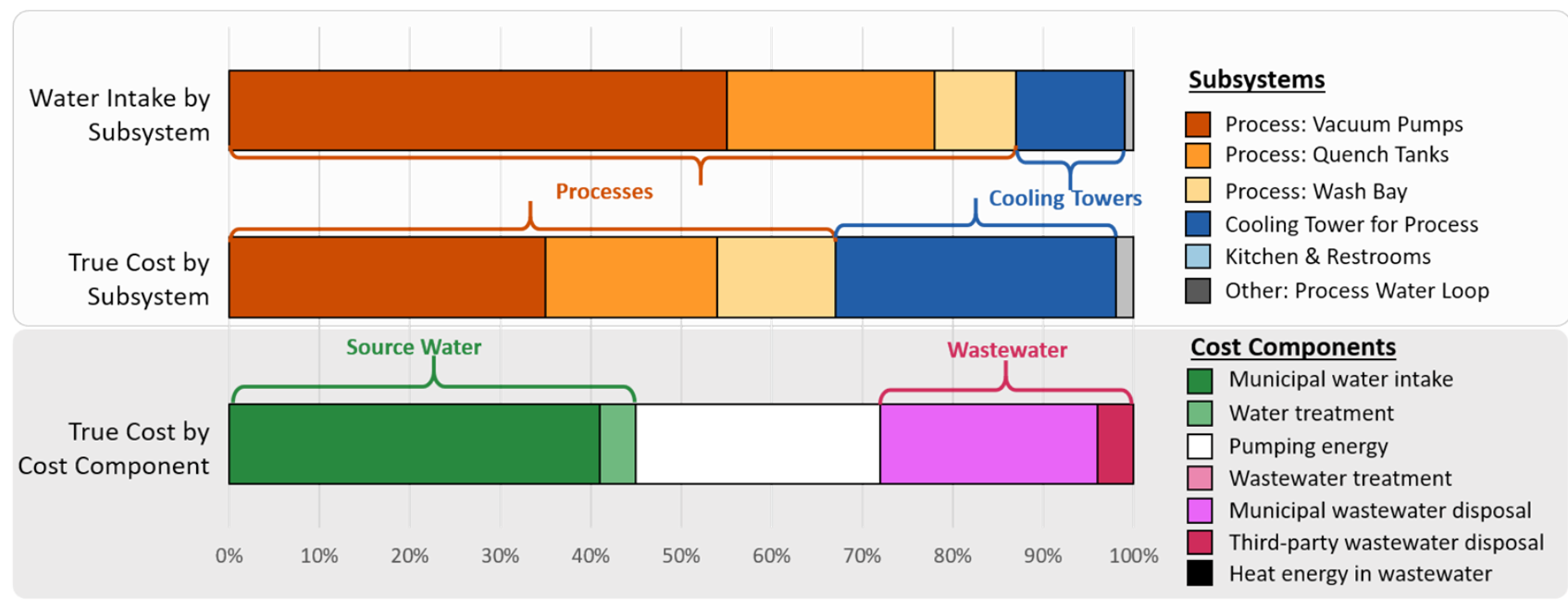

Figure 12. Water use and true cost by subsystem and cost component for the vinyl siding manufacturing plant (Pilot Training 3). 


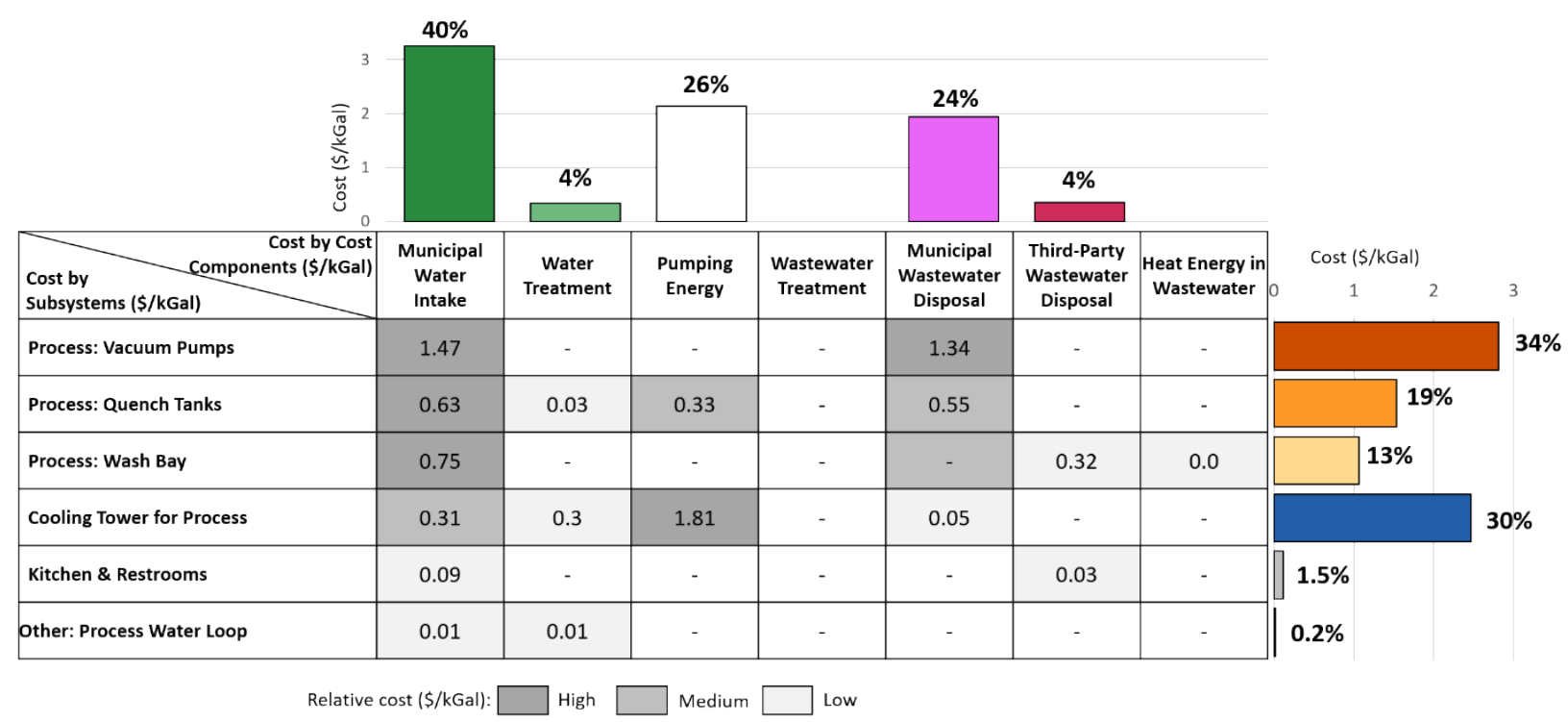

Figure 13. True cost of water by subsystem (rows) and by cost components (columns) for the vinyl siding manufacturing plant (Pilot Training 3).

The PWP exercise helped the facility identify water-intensive and cost-intensive subsystems at the facility. Based on this, appropriate areas where chosen for optimization and teams were put together to investigate the relevant water end users. The teams identified opportunities for water savings, and with the subsystem-level water flows determined using the PWP tool, the water and true cost savings from implementing these measures was determined. The best practices being followed in these areas were also identified as part of this activity.

Facility-level sustainability targets are being pursued. The use of submetering was observed in the plant. However, submetering production water would help understand water flows better. The cooling tower was found to be operated with high cycles of concentration. The recirculation of water in vacuum pumps system was among the best practices followed at this plant. However, pumping energy for recirculation could be reduced with better controls. Vacuum pumps were found to be the single biggest user of water and the most cost intensive. The second most cost-intensive component was the cooling of process water.

The water savings opportunities identified at this plant included installing automated quench tank water level controller, installing variable speed drives on process pumps, bypassing chiller during winter, installing low flow nozzles in wash bay, and managing leaks in sizer area drips. With the subsystem-level water flows determined using the PWP tool, the water and true cost savings from implementing these measures was determined. 


\section{DISCUSSION}

The PWP tool is a comprehensive tool designed for use by manufacturing plants falling under NAICS (North American Industry Classification System) Codes 31, 32, and 33 to help their sustainability teams (1) understand the procurement, use, and disposal of water in their plants; (2) recognize the "true cost" of water, including the costs associated with water procurement, treatment, and consumption and wastewater disposal; and (3) identify opportunities for reducing water use and achieving associated cost savings.

Water-using subsystems in industrial manufacturing plants include processes, cooling and condensing subsystems for process, power generation, and air-conditioning; steam boilers for power generation; and ancillary services such as kitchen, restrooms, landscaping and irrigation, and fire sprinkler subsystems. The PWP tool, in its Microsoft Excel version (PWPEx), has helped facilities by breaking down the total plant water intake, wastewater disposal, and true cost of water by individual subsystems in the plant. By doing so, it has assisted facilities identifying components that contribute the most toward the facility's true cost of water and the most water-intensive subsystems. Results from the implementation of PWP in a facility can also be used to establish a baseline and track water use during subsequent years.

PWP Tool uses a water mass-balance approach to characterize inflows, outflows, and water flows within the facility. The systematic approach allows the estimation of water losses and potential savings. While the tool allows and encourages the use of high-granularity data, it is well known that there are challenges in submetering water flows in the manufacturing sector. PWP provides a way of estimating water use in case data cannot be collected at the moment of analysis. The use of calculated water uses as opposed to using accurately collected data has its drawbacks and may not allow facilities to properly identify losses and opportunities. Through continuous metering and submetering of water, by using appropriate tools to track water-use variability, and by assessing the water mass balance, facilities can acknowledge opportunities for improvement in the identification of losses from water leaks, increased costs of wastewater treatment due stormwater intrusion, as well as water recirculation opportunities.

The PWP tool assesses the water efficiency status of a plant and its individual subsystems and provides a tailored list of water efficiency measures and opportunities specific to the plant. Thus, the PWP tool is a "first step" that industrial manufacturing plants can follow to minimize their water use and achieve cost savings.

Three Water INPLTs have been conducted in manufacturing facilities in the United States. A summary of these efforts and outcomes is presented in Table 10. 
Table 9. Summary of Pilot Water INPLT.

\begin{tabular}{|l|l|l|l|}
\hline \multicolumn{1}{|c|}{ Pilot Training 1 } & \multicolumn{1}{c|}{ Pilot Training 2 } & \multicolumn{1}{c|}{ Pilot Training 3 } \\
\hline No. of participants & 20 & 10 & 11 \\
\hline Industry type & Iron and Steel & Fiberglass & Vinyl Siding \\
\hline Plant boundary & Cold Mill & Entire plant & Entire plant \\
\hline $\begin{array}{l}\text { Main water using } \\
\text { subsystems }\end{array}$ & $\begin{array}{l}\text { Cooling towers, Processes } \\
\text { (cooling and washing) }\end{array}$ & $\begin{array}{l}\text { Cooling towers, Process } \\
\text { (RO Water), Cleaning }\end{array}$ & $\begin{array}{l}\text { Process, Cooling towers, } \\
\text { Cleaning }\end{array}$ \\
\hline Intake water source & $\begin{array}{l}\text { Municipal water (also, } \\
\text { river water for other areas } \\
\text { of the plant) }\end{array}$ & Groundwater & Municipal water \\
\hline Discharge outlets & River, Onsite Lagoon & $\begin{array}{l}\text { Municipal sewer, Industrial } \\
\text { sewer }\end{array}$ & Municipal sewer \\
\hline Source water use & $\begin{array}{l}0.12 \mathrm{kGal} \text { per metric ton } \\
\text { production }\end{array}$ & $\begin{array}{l}0.57 \mathrm{kGal} \text { per metric ton } \\
\text { production }\end{array}$ & $\begin{array}{l}0.33 \mathrm{kGal} \text { per } 1000 \mathrm{lb} \\
\text { production }\end{array}$ \\
\hline True cost of water & $\begin{array}{l}\text { \$ 5.88 per kGal } \\
(1.32 \text { times direct cost })\end{array}$ & $\begin{array}{l}\text { \$ 6.48 per kGal } \\
(3.15 \text { times direct cost })\end{array}$ & $\begin{array}{l}\text { \$ 8.01 per kGal } \\
(1.45 \text { times direct cost })\end{array}$ \\
\hline
\end{tabular}

\subsection{LESSONS LEARNED FROM VALIDATION EFFORTS}

\subsubsection{Analysis Approaches and Findings}

During the implementation of the PWP tool, ORNL identified several findings and strategies to adapt the tool to different manufacturing sectors, facilities of different sizes, and different production processes such as the following.

1. Processes/production lines that have same water intake sources and discharge outlets can be grouped to simplify data collection and water balancing.

2. A water flow diagram and/or a master table with the identified groups and associated treatment processes help better understand water use and streamline the inputs for the PWP tool (Guidelines and Templates available).

3. For very large facilities, breaking down the plant into areas of manageable sizes and developing associated water flows and PWP models are effective.

4. True cost components are unique to each facility. Facilities with similar production processes can have very different cost components depending on water intake sources, discharge requirements, pumping infrastructure, etc.

5. Some facilities have two separate discharges to the municipality (industrial and domestic) and usually have a different sewer cost; they should be considered separately in the analysis. In some cases, the municipal water intake could also have a separate domestic and industrial use meter, and the cost difference between them could be significant.

6. There is a growing interest in water conservation, and developing a sector-specific PWP tool will be well received. 


\subsubsection{Data Collection Challenges}

The INPLTs at the three facilities described in Section 3 revealed challenges that are pervasive in many manufacturing facilities such as the following.

1. Facilities do not always meter or track self-supplied water from on-site wells, surface water sources, etc.

2. Lack of metering and submetering on the subsystem level makes it difficult to acquire subsystemlevel water use.

3. Individual subsystem-level discharges are difficult to meter as they usually drain to the facility outlet by gravity via underground channels which are hard to access.

4. Rainfall-derived infiltration and inflow (RDII) is difficult to estimate and causes errors to water balancing as it is typically drained to the same facility outlet.

5. Finding the right location to install strap-on ultrasonic flow meters for spot measurement is challenging. They require a clean pipe with a straight mounting section with a length at least 20-25 times its diameter and located away from any constriction points for accurate readings.

6. Behavior-driven water consumption (e.g., open spraying) varies significantly between shifts, making it hard to accurately estimate without continuous monitoring.

\subsection{OPPORTUNITIES AND FUTURE WORK}

There are numerous opportunities for facilities to improve their water efficiency and/or associated costs to reach their sustainability goals or reduce water-related risks. Corporations can benefit from defining clear goals and desired outcomes in any sustainability-related effort. The PWP tool helps facilities examine water use and true cost at the subsystem level and identify areas of greatest opportunities for improvement. Depending on the priorities of each facility, selecting from a list of process improvements with different potential outcomes may be required. For instance, there may be facilities exposed to regional water scarcity that are interested in reducing their intake water and discharges at the expense of increased energy use due to onsite wastewater treatment for recirculation.

The importance of metering and submetering is highlighted throughout this report. Facilities can benefit from creating a water management plan that includes water use at the facility level, including selfsupplied water. The submetering of water use for specific processes is also crucial for planning improvements and optimizing resources. In cases where water use data are already being collected, it is important to emphasize the value of adequate data management practices that will allow facilities to extract useful information to make informed decisions.

There are diverse opportunities for facilities to apply advanced technologies for data management that can help optimize resources within a facility. Some of these technologies include advanced water meters, smart water quality sensors, Internet of Things (IoT) technologies that use networks of connected water quality or flow sensors, data aggregation and visualization in dashboards, and supervisory control and data acquisition (SCADA) systems that collect real-time data that allow smart decisions making and improve efficiency.

While there are multiple opportunities to improve water efficiency in a manufacturing facility, this report highlights the importance of the assessment of the true cost of water. The nominal cost paid by facilities 
to acquire water partially reflects the cost of the using water as a means of production. Measuring all the costs associated with water use can lead to the identification of cost-intensive operations in which optimization of water use can yield significant financial returns.

Future work will focus on the implementation of PWP to a wider variety of manufacturing sectors and tracking the benefits obtained by using the true cost of water as a metric for resource optimization. Additional effort may be made to include indirect costs associated with the true cost of water such as capital costs, permit fees, or even the cost of externalities related to the environmental cost of water use. 


\section{REFERENCES}

Alkadi, N., Nimbalkar, S., Fontaine, A. d., \& Schoeneborn, F. (2013). The DOE's In-Plant Training (INPLT) Model to Promote Energy Efficiency in the Industrial Sector. Paper presented at the ACEEE Summer Study on Energy Efficiency in Industry, Niagara Falls, New York.

AWWA. (2006). Water Audit Software. Retrieved from

Becker, R. (2015). Water Use and Conservation in Manufacturing: Evidence from U.S. Microdata. Retrieved from https://www2.census.gov/ces/wp/2015/CES-WP-15-16.pdf

BIER. (2018). BIER True Cost of Water Toolkit 2.0. Retrieved from

Borgomeo, E. M.-N., Mohammad, Hall, J., \& Guillod, B. (2018). Risk, Robustness and Water Resources Planning Under Uncertainty.

Boyd, B. (2011). Guidelines for Estimating Unmetered Industrial Water Use. Retrieved from https://www.energy.gov/sites/prod/files/2013/10/f3/est unmetered industrial wtr.pdf

Carnegie Mellon University Green Design Institute. (2018). Economic Input-Output Life Cycle Assessment (EIO-LCA) US 2002 (428 sectors) Producer model [Internet]. Retrieved from http://www.eiolca.net/. Retrieved 2018 http://www.eiolca.net/

Carollo. (2016). Blue Plan-It. Retrieved from

CDP. (2018). Treading Water. Corporate Responses to Rising Water Challenges. Retrieved from

CheCalc. (2017). Cooling Tower Makeup Water. Retrieved from https://checalc.com/solved/ctmakeup.html

City of Richmond. Cooling-Tower, Irrigation Sub-Metering Requirements. Retrieved from City of Richmond, Virginia: http://www.richmondgov.com/PublicUtilities/documents/DPUForm_CoolingTowerSubMeteringPermit.pdf

City of San Diego. (2020). Fee Schedule For Mechanical, Electrical, Plumbing/Gas Permits. Retrieved from City of San Diego, CA:

Colgate-Palmolive. (2015). Sustainability Report 2014. Retrieved from

Dieter, C. A., Maupin, M. A., Caldwell, R. R., Harris, M. A., Ivahnenko, T. I., Lovelace, J. K., . . . Linsey, K. S. (2018). Estimated use of water in the United States in 2015. Retrieved from https://www.usgs.gov/mission-areas/water-resources/science/industrial-water-use?qtscience center_objects $=0 \#$ qt-science_center_objects

Dorjets, V. (2014). Many newer power plants have cooling systems that reuse water. Retrieved from https://www.eia.gov/todayinenergy/detail.php?id=14971

EDF-GEMI. (2014). WaterMAPP: A Water Management Application Efficiency Toolkit. Retrieved from

Ellis, M., Dillich, S., \& Margolis, N. (2001). Industrial Water Use and its Energy Implications. Retrieved from https://www.aceee.org/files/proceedings/2001/data/papers/SS01_Panel1_Paper03.pdf

EPA. (2011). Lean and Water Toolkit: Achieving Process Excellence Through Water Efficiency. Retrieved from

Fehl, R. (2017). Flow Measurement Management Enables Total Visibility Of Water Use. Retrieved from https://www.wateronline.com/doc/flow-measurement-management-enables-total-visibility-ofwater-use-0001

FEMP. (2016). Water Project Screening Tool. Retrieved from

GEMI. (2002). Collecting the Drops: A Water Sustainability Planner. In: Global Environmental Management Initiative.

Gleick, P. H., Dana; Henges-Jeck, Christine; Srinivasan, Veena; Wolff, Gary; Kao Cushing, Katherine; Mann, Aamardip. (2003). Waste Not, Want Not: The Potential for Urban Water Conservation in California. Retrieved from 
Gouws, J. F., Majozi, T., Foo, D. C. Y., Chen, C.-L., \& Lee, J.-Y. (2010). Water Minimization Techniques for Batch Processes. Industrial \& Engineering Chemistry Research, 49(19), 88778893. doi:10.1021/ie100130a

Guo, W., Wenning, T., Nimbalkar, S., Travis, J., \& Levine, E. (2019). US DOE In-Plant Trainings to Develop Expertise and Replicate Success. Paper presented at the ACEEE Summer Study on Energy Efficiency in Industry, Portland, Oregon.

Henderson, K., Somers, K., \& Stuchtey, M. (2013). Measuring the real cost of water. McKinsey Quarterly. Retrieved from https://www.mckinsey.com/business-functions/sustainability/ourinsights/measuring-the-real-cost-of-water

Kenny, J., Barber, N., Hutson, S., Linsey, K., Lovelace, J., \& Maupin, M. (2009). USGS Circular 1344: Estimated Use of Water in the United States in 2005. Retrieved from https://pubs.usgs.gov/circ/1344/

Kenway, S., Gregory, A., \& McMahon, J. (2011). Urban Water Mass Balance Analysis. Journal of Industrial Ecology, 15(5), 693-706. doi:10.1111/j.1530-9290.2011.00357.x

Kurle, D., Herrmann, C., \& Thiede, S. (2017). Unlocking water efficiency improvements in manufacturing - From approach to tool support. CIRP Journal of Manufacturing Science and Technology, 19, 7-18. doi:10.1016/j.cirpj.2017.02.004

Larson, W. F., Paul; Passinsky, Viktor; Grubb, Edward; Adriaens, Peter. (2012). Mitigating Corporate Water Risk: Financial Market Tools and Supply Management Strategies. Retrieved from

Morrison, J. M., Mari; Murphy, Michael; Schulte, Peter. (2009). Water Scarcity and Climate Change: Growing Risks for Business \& Investors. Retrieved from

Mousavi, S., Kara, S., \& Kornfeld, B. (2015). Assessing the impact of embodied water in manufacturing systems. Paper presented at the CIRP conference on Life Cycle Engineering.

Nestlé. (2013). The Nestlé Policy on Environmental Sustainability. Retrieved from

New Mexico Office of the State Engineer. (1999). A Water Conservation Guide for Commercial, Institutional and Industrial Users. Retrieved from https://www.ose.state.nm.us/WUC/PDF/ciiusers-guide.pdf

Orr, S., Cartwright, A., \& Tickner, D. (2009). Understanding Water Risks. Retrieved from

PepsiCo. (2017). PepsiCo Sustainability Report. Retrieved from

Pham, T. T., Mai, T. D., Pham, T. D., Hoang, M. T., Nguyen, M. K., \& Pham, T. T. (2016). Industrial water mass balance as a tool for water management in industrial parks. Water Resources and Industry, 13, 14-21. doi:10.1016/j.wri.2016.04.001

Rao, P., McKane, A., \& Fontaine, A. d. (2015). Energy Savings from Industrial Water Reductions. Paper presented at the American Council for an Energy-Efficient Economy Buffalo, NY.

Rao, P., Sholes, D., Morrow, W., \& Cresko, J. (2017). Estimating US Manufacturing Water Use. Paper presented at the ACEEE Summer Study on Energy Efficiency in Industry.

Renzetti, S. (1993). Examining the differences in self- and publicly supplied firms' water demands. Land Economics, 69(2), 181-189.

Rogers, P. (1993). America's Water: Federal Roles and Responsibilities. Cambridge, Mass.: Massachusetts Institute of Technology Press.

Rogers, P., de Silva, R., \& Bhatia, R. (2002). Water is an economic good: How to use prices to promote equity, efficiency, and sustainability. Water Policy, 4(1), 1-17. doi:10.1016/s13667017(02)00004-1

Rogers, P., Llamas, R., \& Martinez-Cortina, L. (2006). Water Crisis: Myth or Reality? London: Taylor \& Francis.

Sachidananda, M., \& Rahimifard, S. (2012). Reduction of Water Consumption within Manufacturing Applications. Paper presented at the Leveraging Technology for a Sustainable World

Seneviratne, M. (2006). A Practical Approach to Water Conservation for Commercial and Industrial Facilities: Elsevier Science.

Solley, W. B., Pierce, R. R., \& Perlman, H. A. (1998). Estimated use of water in the United States in 1995. doi:10.3133/cir1200 
Statistics Canada. (2018). Special tabulation, based on 2013 Industrial Water Survey. Retrieved from Thiede, S., Schönemann, M., Kurle, D., \& Herrmann, C. (2016). Multi-level simulation in manufacturing companies: The water-energy nexus case. Journal of Cleaner Production, 139, 1118-1127. doi:10.1016/j.jclepro.2016.08.144

Trueblood, A., Chow, S., Ritchie, M., \& Ganji, A. (2015). Water and Embedded Energy Conservation in the Industrial Sector-Potentials and Case Studies. Paper presented at the Industrial Energy Technology Conference New Orleans, LA.

U.S. Department of Energy. (2014). The Water-Energy Nexus: Challenges and Opportunities. Retrieved from

U.S. Department of Energy. (2016). Better Buildings Water Sanvings Initiaitve. Retrieved from https://betterbuildingssolutioncenter.energy.gov/better-plants/water-savings-initiative

U.S. EPA. (2011). Lean \& Water Toolkit-Achieving Process Excellence Through Water Efficiency. Retrieved from https://doi.org/EPA-100-K-11-003

UN. (2007). Coping with Water Scarcity: Challenge of the Twenty-First Century. Retrieved from Veolia. (2013). Veolia True Cost of Water.

Walsh, B. P., Bruton, K., \& O'Sullivan, D. T. J. (2017). The true value of water: A case-study in manufacturing process water-management. Journal of Cleaner Production, 141, 551-567. doi:10.1016/j.jclepro.2016.09.106 